\title{
Pronoun ambiguity resolution in Greek: Evidence from monolingual adults and children
}

\author{
Despina Papadopoulou ${ }^{a, *}$, Eleni Peristeri ${ }^{a}$, Evagelia Plemenou ${ }^{b}$, \\ Theodoros Marinis ${ }^{\mathrm{C}}$, lanthi Tsimpli ${ }^{\mathrm{a}}$ \\ ${ }^{\text {a }}$ Aristotle University of Thessaloniki, Greece \\ ${ }^{\mathrm{b}}$ Panteion University, Greece \\ ${ }^{c}$ University of Reading, England, United Kingdom
}

\begin{abstract}
A large body of psycholinguistic research has revealed that during sentence interpretation adults coordinate multiple sources of information. Particularly, they draw both on linguistic properties of the message and on information from the context to constrain their interpretations. Relatively little however is known about how this integrative processor develops through language acquisition and about how children process language. In this study, two on-line picture verification tasks were used to examine how 1 st, 2 nd and 4 th/5th grade monolingual Greek children resolve pronoun ambiguities during sentence interpretation and how their performance compares to that of adults on the same tasks. Specifically, we manipulated the type of subject pronoun, i.e. null or overt, and examined how this affected participants' preferences for competing antecedents, i.e. in the subject or object position. The results revealed both similarities and differences in how adults and the various child groups comprehended ambiguous pronominal forms. Particularly, although adults and children alike showed sensitivity to the distribution of overt and null subject pronouns, this did not always lead to convergent interpretation preferences.
\end{abstract}

Keywords: Pronoun resolution; Null and overt pronominals; Greek; Language development

\section{Introduction}

Over the past 20 years an accumulating body of evidence on sentence processing has shown that a wide range of syntactic and non-syntactic sources of information mediates sentence interpretation. For example, semantic plausibility, syntactic information, relevant contextual information, statistical regularities, and frequency of lexical co-occurrence have all been found to inform adults' parsing commitments (Altmann and Steedman, 1988; Pearlmutter and MacDonald, 1995; Taraban and McClelland, 1988; Tanenhaus and Trueswell, 1995; Trueswell, 1996; Trueswell and Tanenhaus, 1994; Trueswell et al., 1994).

Although there is plenty of evidence that adults are capable of coordinating these types of information, it is unclear whether the same applies to children. Recent research on the nature of children's sentence processing abilities has attempted to unify theories of language processing and language development and to examine how the processing system develops in children (e.g., Clahsen and Felser, 2006; Felser et al., 2003b; Goodluck, 1990; Goodluck and Tavakolian, 1982; McKee et al., 1993; Papadopoulou and Tsimpli, 2005; Trueswell et al., 1999; Tyler and Marslen-Wilson, 1981).

\footnotetext{
* Corresponding author at: Department of Linguistics, School of Philology, Aristotle University of Thessaloniki, Thessaloniki 54 124, Greece. E-mail address: depapa@lit.auth.gr (D. Papadopoulou).
} 
One phenomenon that requires the coordination of different types of information is pronoun resolution in null subject languages, where the choice of subject pronoun form (overt or null) is regulated by discourse factors. In this paper, we present the results of two experiments that are designed to examine how Greek children and adults coordinate grammatical and discourse pragmatic information in order to resolve pronoun ambiguities during sentence interpretation. The focus is on the resolution of overt and null subject pronouns whose distribution in Greek is regulated by discourse factors. If children have acquired the grammatical and discourse pragmatic principles of pronoun distribution, then we would expect their interpretation preferences to be the same as those of adults and to vary as a function of pronoun form. To explore this research question we employed a self-paced listening picture verification task in which we investigated both the participants' pronoun resolution preferences and processing patterns as revealed from listening times on particular words/zones of the critical stimuli. Our findings indicate that, whereas adults have an established subject preference for null pronominal forms and an object preference for overt pronouns, children show a distinct developmental pattern for null and overt pronouns. In particular, the resolution of overt pronouns is adult-like in 10-to-11-year-old children, but not steady in younger child groups, although they too seem to be sensitive to the appropriate discourse feature during sentence processing. On the other hand, null pronouns reveal a U-shaped development with no clear resolution pattern even at the age of 10 -to-11 years.

In section 2, we first give a brief overview of pronominal subjects in Greek, while current accounts as well as empirical data on the interpretation of null and overt pronouns are outlined in section 3. In section 4 we review studies on the acquisition of null and overt subjects in null-subject languages. In section 5 we describe the experiments that we conducted and report on their results; first, we describe the experiment investigating null (section 5.1) and secondly the one testing overt subject pronouns (section 5.2). In section 6 we discuss the results from both experiments and their implications for current theories of language processing in children. In section 7 we draw a number of conclusions from the evidence provided.

\section{Distribution of null and overt subject pronouns in Greek}

Greek is a null-subject language, that is, it allows null subjects in finite clauses as shown by the example in (1):

(1)
Xtes
pro ísa
to
Jáni.
yesterday pro saw-PERF-1SG the-ACC Jani-ACC
"Yesterday I saw John."

However, the repertoire of pronominal forms in Greek consists of both null and overt pronouns. The null pronominal option is a weak pronoun and is considered to be the default form, whereas the overt pronominal form is a strong pronoun and constitutes the "marked" option (Cardinaletti and Starke, 2001; Montalbetti, 1984). For example, the null and overt pronouns in (2a) and (2b) respectively, though ambiguous, exhibit specific preferences with respect to their reference. Namely, the null pronoun in (2a), being the default pronominal form in Greek, is preferably anchored to the most salient/ prominent referent, i.e. the sentential subject/topic, and hence leads to a non-shifted interpretation for the subject. On the other hand, the overt pronoun in ( $2 b$ ), when pronounced as unstressed, marks topic shift and is preferably associated with less salient/prominent entities of the discourse, i.e. non-topic referents. Notice that such a referent could be either the complement of the main clause, tin kopéla, or a third referent not mentioned in the main clause ${ }^{1}$ :

$$
\begin{aligned}
& \text { O papús milúse Sinatá ston egonó tu ótan pro jjávaze } \\
& \text { the old-man spoke-IMP-3SG loudly to-the grandson his when pro read-PAST- } \\
& \text { "The old-man was speaking loudly to his grandson when he was reading a book." }
\end{aligned}
$$

I jajá xerétise $\quad$ tin kopéla ótan aftí pernúse
the old-lady greeted-PERF-3SG the girl when she crossed-IMP-3SG the street
"The old-lady greeted the girl when SHE was crossing the street."

Consider further the interpretation of null and overt subject pronouns in (3). The null pronoun in (3b) is straightforwardly anchored to the topic of the previous utterance, o Pétros, introduced in (3a). Notice, however, that the use of an unstressed overt pronoun in (3c) to refer to the previous topic makes the sentence sound awkward. However, (3c) becomes easily acceptable and acquires additional readings, if the overt pronoun is stressed as in (3d). Namely, the presence of a stressed overt pronoun with a high pitch accent associated with contrastive focus in (3d) implies that Peter

\footnotetext{
${ }^{1}$ The third referent option is indeed highly marked, as an anonymous reviewer mentions, and requires contextual (discourse or visual) supporting cues. In our experimental tasks we included pictures with a third referent as a possible antecedent.
} 
greeted Mary and no one else did. If, on the other hand the stressed pronoun carries an accent linked with contrastive topic the speaker asserts that Peter greeted Mary but someone else did not. ${ }^{2}$

$\begin{array}{lllll}\text { Xerétise } & \text { o } & \text { Pétros } & \text { ti } & \text { María; } \\ \text { greeted-3SG } & \text { the-NOM } & \text { Petros-NOM } & \text { the-ACC } & \text { Maria-ACC }\end{array}$

"Did Petros greet Maria?"

(3b) $\mathrm{Ne}$, pro ti xerétise.

yes pro her-greeted-3SG

"Yes, he greeted her."

(3c) \#Ne, aftós ti xerétise.

yes he her-greeted-3SG

"Yes, he greeted her."

(3d) Ne, AFTOS F/CT ti xerétise.

yes he her-greeted-3SG

"Yes, HE greeted her."

In this study, we focus our discussion on null and unstressed overt subject pronouns and our aim is to experimentally investigate in adults and three child groups whether their interpretation is affected by the salience/prominence of the antecedent. Given the complex mappings between referring expressions and antecedents, the interpretation of subject pronouns in Greek requires the coordination of grammatical and pragmatic knowledge. Knowledge of grammar provides language users with the option of an overt or null pronoun as the subject of a finite clause. Knowledge of pragmatics guides the choice of pronoun form given the discourse context. The most underspecified form of reference available in Greek, pro, should pick a subject antecedent, whereas a fully specified form should pick a less salient, non-subject antecedent.

\section{Accounts of pronoun ambiguity resolution}

Pronoun resolution in a null subject language is a complex task insofar as it draws not only on specific grammatical and pragmatic knowledge, but also on properties of a general and/or language-specific processing mechanism. A theoretical account that makes explicit predictions regarding pronoun resolution patterns is Centering Theory (Brennan et al., 1987; Grosz et al., 1995). According to Centering Theory, pronouns prefer to have antecedents in the subject position. Furthermore, prominence of an antecedent is defined as a list of "forward looking centers", i.e. available referents, where the highest member of the list is the most compatible antecedent. Compatibility is defined structurally, e.g. in terms of $\varphi$ features, and thematically in terms of agentivity (Grosz et al., 1995). It should be noted here that the discourse notions of salience and prominence have been considered as the key determinants of anaphora resolution by several researchers despite differences in the way they have been defined, e.g. Topicality by Givon (1983), Accessibility by Ariel (1990), Givenness by Gundel et al. (1993), or Informativeness by Allen (1997). ${ }^{3}$

Another theoretical account, which has been proposed more recently, is the Position of Antecedent Strategy (PAS) postulated by Carminati (2002). PAS differs from Centering Theory in that it associates a particular structural position, i.e. Spec IP, with specific discourse properties, as explicitly exemplified below. Carminati (2002) experimentally tested pronoun resolution in a null-subject language, i.e. Italian, by conducting on-line and off-line experiments. The findings of these experiments revealed that null and overt subject pronouns have distinct biases toward the syntactic position of their antecedent. Namely, she found that null pronouns manifest a preference to be linked with subject antecedents, while overt pronouns are biased toward non-subject antecedents. These results have been replicated more recently by Filiaci (2010). Based on this evidence, Carminati proposed the PAS in resolving intra-sentential anaphora, according to which the null pronoun prefers an antecedent which is in the canonical subject position, i.e. in the Spec IP position, whereas the overt pronoun prefers an antecedent which is not in the Spec IP position. This structural preference is in line with a discourse principle whereby the more salient entities are referenced with the most reduced form, along the lines of the accessibility hierarchy proposed by Ariel (1990). Given that the entity introduced by the subject is normally considered the default topic of the sentence, hence highly accessible in memory, it will be picked as the referent for a null rather than for an overt pronoun, as less informative, less rigid and more attenuated markers are linked with prominent entities. The opposite

\footnotetext{
${ }^{2}$ We thank an anonymous reviewer for pointing out these interpretative differences between stressed and unstressed overt subject pronouns.

${ }^{3}$ Another account that attempts to capture the pronoun resolution patterns is the Parallel Preference Account (Chambers and Smyth, 1998), which predicts that pronouns prefer antecedents in a parallel position when certain conditions are met. Thus, subject pronouns should prefer subject antecedents and object pronouns should prefer object antecedents. However, causal inference based accounts (Ehrlich, 1980; Kehler, 2002) argue that causal inferences rather than the parallel syntactic position of the pronouns and their antecedents better explain pronoun resolution strategies. The experimental items of the present study do not manipulate such factors and, thus, these proposals will not be further discussed.
} 
pattern is expected for overt pronouns: being more informative, more rigid and less attenuated markers, overt pronouns prefer less prominent discourse entities as referents.

The PAS proposed by Carminati (2002) has been further investigated in several Spanish studies on pronoun resolution. Alonso-Ovalle et al. (2002) conducted an off-line questionnaire study in which the participants were asked to denote the referent of null and overt pronominals, when these were preceded by a sentence containing two possible referents, one in the subject and one in the object position. The findings indicated that the null pronoun was preferably anchored with the subject of the previous utterance, while the linking of the overt pronoun to the subject antecedent was attested approximately $50 \%$. These findings have been recently replicated by Jegerski et al. (2011) as well as by Keating et al. (2011). Moreover, Filiaci (2010) conducted two self-paced reading tasks, one in Italian and one in Spanish, using Carminati's experimental materials. The Italian experiment reproduced the findings reported in Carminati (2002). The Spanish results, however, were similar to those reported in the aforementioned questionnaire studies. Namely, Filiaci found processing cost associated with the linking of null pronominals to non-salient/prominent antecedents, while overt pronouns did not exhibit processing cost when referring to salient antecedents. Therefore, the Spanish studies suggest that cross-linguistic differences exist even among null subject languages. In particular, resolution of overt pronominals displays a clear bias toward non-salient antecedents in Italian (Carminati, 2002; Tsimpli et al., 2004), while in Spanish they do not seem to comply with the discourse feature of salience/prominence. In a study on Catalan (Mayol and Clark, 2010), however, the PAS has been supported by both offline and online data, even though the dispreference of overt pronominals to refer to topic antecedents was not as strong as in the Italian (Carminati, 2002; Filiaci, 2010) study.

Tsimpli et al. (2004) also explored the resolution preferences of null and overt pronouns in Italian. Their findings provide support for the differential status of the two pronominal forms, as suggested by the aforementioned accounts (Ariel, 1990; Carminati, 2002). In particular, Tsimpli et al. (2004) investigated forward and backward anaphora resolution in adult native speakers of Italian by means of a sentence-picture matching task. Participants heard sentences consisting of a main and a subordinate clause; the main clause introduced two referents, one in the subject and one in the object position. The subject of the subordinate clause was either a null or an overt pronoun and participants had to select the referent for the null or overt pronoun by choosing one of three pictures. One picture corresponded to the subject and one to the object of the main clause. The third picture depicted a new referent who was not introduced in the sentence. The findings showed that in sentences with forward anaphora, when the subject of the subordinate clause was a null pronoun, participants preferred to interpret it as the subject of the main clause. In contrast, when the subject of the subordinate clause was an overt pronoun, participants strongly preferred to interpret it as referring to the new referent. In sentences with backward anaphora, when the subject of the subordinate clause was a null pronoun, participants allowed for either the subject or the object of the main clause as a possible referent. However, when the embedded subject was an overt pronoun, participants showed a strong preference for the matrix object to be the referent of the pronoun. These findings are in line with proposals put forward by Ariel (1990) and Carminati (2002) on anaphora resolution in null subject languages, according to which the pronoun form and the prominence of the compatible antecedents have an impact on reference options. Furthermore, Tsimpli et al.'s results resemble those attested in Carminati (2002) and replicated by Filiaci (2010), in that the two pronoun forms display distinct reference choices. Nevertheless, in Tsimpli et al.'s study the null subject pronouns were not found to be restricted to the subject referent in backward anaphora, in contrast to Carminati's results. Notice, however, that this difference between Tsimpli et al. on the one hand and Carminati (2002) and Filiaci (2010) on the other may be attributed to the different nature of the tasks employed in the two studies, even though we cannot provide a straightforward explanation of this discrepancy. Furthermore, the study by Tsimpli et al. reports divergent results for forward and backward anaphora, indicating that the ordering of the pronouns and the antecedents may have an impact on pronoun resolution. Interestingly, the overt pronoun in sentences involving forward anaphora preferably refers to the third referent, rather than to the complement of the main clause, as is the case in backward anaphora. Notice that the third referent has been chosen as a possible antecedent in very few (less than 10\%) instances of all other experimental conditions; this is expected, since the activation of the third referent, not being present in the sentential context given to the participants, is costly. It seems, however, that the presence of an overt pronominal in forward anaphora sentences makes this option preferable.

Turning to studies investigating pronoun resolution strategies in Greek, Dimitriadis (1996), based on the theoretical assumptions of Centering theory as well as on Greek corpus-data, argues that the reference routines attested with the two types of pronominals, null and overt, are inherent in their lexical entries. More specifically, overt subject pronouns cannot be construed with the most prominent antecedent of the previous utterance. On the other hand, null pronouns are construed with the highest compatible antecedent from the available list of referents. This "distribution of labor" between null and overt pronouns is not, however, without exceptions. Although it partly relies on the lexical properties of the pronoun form, pragmatic considerations may cancel the dictated option, thus, accounting for the non-categorical nature of anaphora resolution. He further argues that the overt pronominal form in Greek exhibits a strong bias, in that its anchoring with salient/prominent antecedents is almost always excluded, while the preference of null pronouns to refer to salient/ prominent antecedents is not that strong. According to Dimitriadis, the reference of overt pronouns is part of their conventionalized meaning and is constrained by the Overt Pronoun Rule, which disallows the dependency between an 
overt pronoun and a salient/prominent antecedent. These theoretical assumptions are supported by the corpus data reported in Dimitriadis (1996).

Miltsakaki (2001, 2007), also working within the framework of Centering theory in Greek, provides corpus data and makes similar suggestions for null and overt pronouns. In particular, she argues that null pronouns tend to refer to the discourse topic, while overt pronouns disprefer reference to the discourse topic, assuming, however, that these biases are equally strong for both pronominal types. Furthermore, Miltsakaki's corpus data (2007) reveal a preference for overt pronominals to refer to patient arguments appearing both in preverbal and postvebral positions.

The Greek corpus data provided by Dimitriadis (1996) and Miltsakaki $(2001,2007)$ are in line with findings from other null subject languages in that the two pronominal forms exhibit different resolution routines (Alonso-Ovalle et al., 2002; Carminati, 2002; Filiaci, 2010; Jegerski et al., 2011; Keating et al., 2011; Mayol and Clark, 2010; Tsimpli et al., 2004). Additionally, the preference of overt pronouns to be linked with non-salient antecedents observed in Italian (Carminati, 2002; Filiaci, 2010; Tsimpli et al., 2004) and Catalan (Mayol and Clark, 2010) is supported by the Greek data. However, the overt pronoun resolution preferences in Greek differ from those attested in Spanish (Alonso-Ovalle et al., 2002; Filiaci, 2010; Jegerski et al., 2011; Keating et al., 2011), where overt pronominals do not demonstrate a strong preference for nonsalient antecedents. Regarding the resolution patterns for null pronouns, Miltsakaki's corpus studies (2001, 2007) indicate a clear preference for salient antecedent; this finding is convergent with the Spanish (Alonso-Ovalle et al., 2002; Filiaci, 2010; Jegerski et al., 2011; Keating et al., 2011), the Catalan (Mayol and Clark, 2010) and the Italian data provided by Carminati (2002) and Filiaci (2010). On the other hand, the corpus data in Dimitriadis' study (1996) denote that the null pronominals in Greek are compatible with both salient and non-salient antecedents; this result agrees with the Italian data from null pronominal forms presented in Tsimpli et al. (2004).

It follows from the above that pronoun interpretation in a null-subject language is driven by a mechanism that is constrained by the specific grammatical and discourse principles of the language. More specifically, the accounts and the studies reviewed in this section indicate that the anaphor resolution strategy employed by speakers integrates both the grammatical properties of the null and overt pronouns as well as the discourse-related features associated with the two forms (Carminati, 2002; Dimitriadis, 1996; Filiaci, 2010; Jegerski et al., 2011; Keating et al., 2011). Furthermore, the data so far indicate that there are cross-linguistic differences (the Italian, Catalan and Greek data vs. the Spanish data on overt subject pronoun resolution) as well as intra-language differences (Dimitriadis's vs. Miltsakaki's study and Carminati's data vs. Tsimpli et al.'s data on null subject pronoun resolution in Greek and Italian respectively) in the way the pronominal forms are preferably interpreted. In the present study, we provide, apart from the child data, Greek adult data on pronoun resolution, which will address the question of what types of information, i.e. grammatical, discourse-level, adult native speakers employ to interpret ambiguous pronominals. Moreover, the present data will be discussed in relation to previous data and theoretical accounts.

\section{Null and overt subject pronouns in child language}

A growing body of research on how children produce and comprehend subject pronouns investigates whether differences attested between adults and children are attributed to a delayed use of discourse factors in on-line sentence comprehension and production, as opposed to the early use of purely grammatical cues.

The language development literature over the last ten years focused on the investigation of child sentence processing by means of various methodologies and addressed the question of how syntactic, semantic and discourse information is employed by children while processing temporarily syntactic ambiguities (self-paced reading and listening studies: Felser et al., 2003a,b; Papadopoulou and Tsimpli, 2005; Traxler, 2002; eye-tracking studies: Trueswell et al., 1999; cross-modal priming tasks: McKee et al., 1993; word-monitoring tasks: Tyler and Marslen-Wilson, 1981; Tyler, 1983; event-related brain potentials: Hahne and Friederici, 2001). What emerges from such studies is that child sentence processing has essentially two sides to it. First, from a language competence standpoint, the question is whether children have in fact acquired the semantic, grammatical, and pragmatic knowledge that underlies comprehension and production. Second, from a language performance standpoint, the question is whether the L1 grammar automatically gives rise to languagespecific or to default processing strategies that are available from the earliest stages of language acquisition.

In pronoun resolution, for example, knowledge of grammar would determine whether the language allows null subjects; knowledge of pragmatics could comprise principles such as that of "informativeness"4 (Greenfield and Smith, 1976), whereby information is linguistically encoded when it pertains to aspects of an event that cannot be easily recovered by an

\footnotetext{
${ }^{4}$ Informativeness is a discourse pragmatic principle which provides an account of argument drop (Clancy, 1993, 1997; Greenfield and Smith, 1976). According to informativeness, argument realization depends upon a number of pragmatic features such as person, absence, contrast, query, differentiation in discourse etc. (Allen, 2000, 2001). The higher the informative values of the pragmatic feature set assigned to an argument the less likely it is for the argument to be dropped. In contrast an argument with only one informative feature assigned such as a $3 \mathrm{rd}$ person referent who is physically present and not new in the discourse is likely to be dropped (Serratrice et al., 2004).
} 
interlocutor, but is omitted when this is highly accessible. In the case of null-subject languages, this is instantiated in a positive correlation between high informativeness and null subjects on the one hand, and between low informativeness and overt subjects on the other.

Although the findings from the child sentence processing literature do not clearly distinguish between 'competence' and 'performance' accounts of the data, they do suggest that it is the latter rather than the former which gives rise to childadult differences. Specifically, it appears that when weaker or no effects of referential factors are found in children's performance, this is not due to a lack of knowledge of pragmatics, but rather to children's inability to rapidly integrate semantic and pragmatic cues in specific tasks when interpreting sentences in real-time. Previous work on syntactic disambiguation in children has demonstrated that children are able to rapidly employ morphological and phrase-structure information on line (Papadopoulou and Tsimpli, 2005; Papangeli, 2010; Papangeli and Marinis, 2009; Roberts et al., 2007) and exhibit a preference for the simplest syntactic analysis disregarding plausibility considerations (Traxler, 2002). Furthermore, Trueswell et al. (1999) showed that children were unable to use contextual information in the resolution of structural ambiguities such as "Put the frog on the napkin in the box" and rather relied solely on phrase structure rules. More specifically, children analyzed the post-verbal PP as the Destination argument of the verb even in an NP-modifier context, unlike adults who were influenced by the type of context in accordance with the principle of Referential Support ${ }^{5}$ (Altmann and Steedman, 1988). Moreover, children are slower in parsing the sentential input (see Clahsen and Felser, 2006 for a review) than adults and their processing strategies are more affected by working memory than the parsing routines employed by adults (Felser et al., 2003a,b). In sum, in the studies presented above children showed greater reliance on structural properties of the input and less or no reliance on discourse cues. It is still a matter of debate whether such findings signal immature pragmatics or a problem with the integration of lexical and pragmatic cues in on-line sentence processing (Trueswell et al., 1999; Clahsen and Felser, 2006 and references therein).

However, other studies have illustrated that children make use of the referential context in off-line tasks. Crain and colleagues, for example, showed that children even by the age of five years were more likely to understand and produce relative clause modifiers when the visual context referentially supported modification (Crain et al., 1990; Hamburger and Crain, 1982) or in off-line tasks when two equally salient potential referents were involved (Meroni and Crain, 2003). Overall, some studies indicated that children's processing relies more on grammatical (syntactic and morphological) rather than semantic and pragmatic information (Felser et al., 2003a,b; Trueswell et al., 1999), although there does exist some evidence to the contrary (e.g. Crain et al., 1990; Hamburger and Crain, 1982; Meroni and Crain, 2003).

In contrast to these findings for comprehension, studies on production have shown that pragmatic cues are employed even by very young children. Studies on the production of subjects in null subject languages reveal that the use of null or overt subjects is clearly regulated by pragmatics. For example, in an analysis of spontaneously produced utterances from two Greek children aged 1;9-2;2 years, Tsimpli (2005) found that the form of the subject produced by the children is affected by discourse-level information, such as information structure. Namely, null subjects were used in almost half of the children's utterances in which the referent was easily recoverable by the context, showing that null subjects are established as the default form in the child grammar, while overt subjects were regulated by discourse factors, e.g. focus. In this respect, a further distinction between preverbal and postverbal subjects is suggested: preverbal subjects, nominal or pronominal, were used when the subject was focused whereas the postverbal position was used for non-focused subjects.

Discourse coreference seems to be another factor affecting the form of the referring expressions. Hickmann and Hendriks (1999) examined the narratives of English, French, Chinese and German children aged from 4 to 10 years and found that pronominals were most frequently used when functioning as coreferential subjects. Moreover, this tendency to link pronouns with unambiguous subject topics became more prominent from the age of 7 years onwards at least for English and Chinese children.

In other studies, the form of the subject has been related to the informativeness features carried by its referent. Serratrice et al. (2004) analyzed two sets of monolingual English and Italian corpora and a bilingual English-Italian corpus of children aged from 1;7 to 4;7 and found that null arguments were systematically associated with uninformative rather than informative features (see footnote 4). Interestingly, this pattern was obtained for a null (Italian) and a non-null (English) subject language alike, indicating that in developing systems the pragmatic principle of informativeness can even override the overt subject syntactic constraint. Thus, in both English and Italian, the distribution of overt and null subjects was regulated by discourse factors. In a further study which assessed the use of word order and morphosyntactic form to signal the distinction between new vs. given information, Serratrice (2007) replicated her earlier findings whereby children use language-specific and pragmatically appropriate referring expressions for the realization of subjects. Furthermore, Argyri and Sorace (2007) investigated the production and off-line acceptability of null and overt

\footnotetext{
${ }^{5}$ According to the principle of Referential Support, resolution of ambiguous phrases such as "Put the frog on the napkin. .." will favor the NPmodification reading when the context provides more than one unique referent (Altmann and Steedman, 1988).
} 
subject pronouns in Greek when there is no topic shift and, thus, the null pronoun option is predicted to be favored over the overt one. Greek children at the age of 7;5-9;7 years and adults always produced a null pronominal in the no topic shift conditions. In the acceptability judgment task, however, even though the Greek adults accepted only the null subject pronoun utterance, the Greek children did not do so consistently. This finding, on the one hand, indicates differences between the two modalities, production and judgment, and, on the other, it reveals developmental differences, in that the children, even at the age of 9 years, seem to accept the overt subject pronoun for salient referents, i.e. topics.

Literature on the processing and interpretation of anaphors suggests that children may be sensitive to different information compared to adults. In an early on-line study, Tyler (1983) examined how 4-, 5-, 7-year-old Dutch children and adults processed anaphoric expressions, full DPs and personal pronouns, and concluded that at the age of 7 years the mechanisms used by children no longer differ from those employed by adults. She also claimed that up to the age of 5 years the children experienced difficulties in rapidly integrating all necessary cues, i.e. grammatical, lexical and contextual, for the anchoring of the anaphoric expressions to the antecedent.

Later studies investigated the impact of discourse factors on the interpretation of pronouns. For example, use of cues contributing to discourse prominence of a pronoun's potential referent, like first-mention and subjecthood, has been well documented in adults (Corbett and Chang, 1983; Arnold et al., 2000), but controversial in children. For instance, Arnold et al.'s (2007) study revealed that 5 year olds, although they rely on grammatical features, such as the gender of the pronoun, to anchor the pronoun with the appropriate antecedent, showed no first-mention bias effect in both off-line and on-line tasks. For example, when the children are orally presented with a sentence which contains two possible antecedents of the same gender, Puppy and Panda Bear, they do not show a reliable preference to the first-mention antecedent, Puppy, in the interpretation of the subject pronoun he.

\section{Puppy is having lunch with Panda Bear. He wants some milk.}

On the other hand, other studies have found first-mention effects in 2-3 year olds (Song and Fisher, 2005, 2007) in off-line story interpretation tasks. More specifically, the 2-3-year-old children prefer to interpret the pronoun he as referring to the first-mention antecedent, the alligator, as do older children and adults:

On a sunny day, the alligator went outside. He went to the tiger's yard. What did he find? He found a bucket.

Notice that, even though both studies focus on the referential properties of the antecedent, i.e. first-mention bias, they arrive at contradictory results. This discrepancy may be due to the intermingling of a grammatical, i.e. gender, and a discourse factor in the former study as well as with the amount and complexity of contextual information given in the two studies. In Song and Fisher's study (2007) the salience of the appropriate antecedent, the alligator, increases with the use of the co-referential pronoun, he, in more than one utterance, while in sentence (5) the disambiguation of the pronoun relies on the selection of the appropriate antecedent which occurs only once in the preceding sentence. Although the sentences in our study contain a subordinate and a main clause and in this respect they are more complex than the ones employed by Arnold et al. (2007), the salience of the antecedents is parallel to this study rather than to the study by Song and Fisher (2007), since the possible antecedents of the ambiguous pronoun are in the immediately previous clause and they occupy the subject and the object position as in (4).

Furthermore Sekerina et al. (2004) conducted eye-tracking experiments in order to investigate the processing of referring expressions in English adults and 4- to 7-year-old children. Their findings indicated that children differed from adults in that they were significantly less likely to choose an extra-sentential, but possible, antecedent for a pronoun than the adults. Additionally, the analysis of children's eye movements showed that children are significantly slower than the adults in detecting the ambiguity, although they show awareness of the ambiguity involved.

The results of the previous studies indicate discrepancies with respect to the early use of discourse constraints in pronoun resolution and they further indicate differences between the modalities of production and comprehension, with spontaneous production being more intact than comprehension. Moreover, the comprehension or interpretation of the ambiguous pronoun seems to be affected by contextual factors supporting the first-mention/subject bias (see Song and Fisher, 2007 vs. Arnold et al., 2007).

The present study aims at exploring the development of the anaphor resolution strategy in Greek by shedding more light on speed and accuracy in which children resolve null and overt pronoun ambiguity with minimal contextual support and without any grammatical gender cue. In particular, we investigate the effects of a grammatical factor, namely the pronominal form, overt vs. null pronouns, and an associated discourse property, topic shift vs. topic continuity, on pronoun resolution in Greek in three age groups of children. Additionally, we employed an on line interpretation task in order to explore whether any discrepancies between the adult and the child data are attributed to immature pragmatics or alternatively to the inefficiency of the child processing mechanism to integrate various information sources on line. 


\section{The present study}

The design employed to test interpretation of null and overt pronouns in backward anaphora in Greek is similar to that employed by Tsimpli et al. (2004), but is implemented in two on-line experiments. More specifically, we investigated pronoun ambiguity resolution of null and overt subject pronouns in sentences with two compatible referents which appear in the subject and object position of the previous clause. Both referents are always animate with agentivity associated with the subject. The discourse feature we examine is a presence vs. absence of a shifted topic interpretation in the use of null and overt pronouns. ${ }^{6}$

\subsection{Experiment 1: Resolution of null pronouns}

\subsubsection{Method}

5.1.1.1. Participants. Thirty six monolingual Greek adults participated in the study (mean age: $30.4 ;$ SD: $5.85 ; 21$ females). Moreover, we tested three groups of children aged from 6;0 to 11;2: (a) twenty monolingual Greek children (10 females) aged from 6;0 to 6;3 years (mean age: 6.10; SD: 0.24) attending the 1st grade of primary school, (b) twenty two monolingual Greek children (10 females) aged from 7;0 to 7;8 years (mean age: $7.35 ;$ SD: 0.28 ) attending the 2nd grade of primary school and (c) thirty one monolingual Greek children (16 females) aged from 10;0 to 11;2 years (mean age: 10.68; SD: 0.35 ) being at the 4 th or 5th grade of the primary school. The choice of the specific age groups was based on the requirements of the task as well as on previous work testing children and adults on pronoun interpretation. The task we employed was a demanding on-line task, in which the participants had to coordinate the oral presentation of a sentence with a possible visual representation of it and, thus, we decided not to run the experiments with children younger than 6 years. Furthermore, studies testing pronoun resolution in children (Arnold et al., 2007; Hickmann and Hendriks, 1999; Tyler, 1983) showed insufficient integration of discourse-internal constraints, like first-mention biases, during pronoun interpretation in 5-year-old preschoolers. This is consistent with claims in the literature that children are beginning to develop pragmatic abilities at the age of 5 years (Verbuk and Roeper, 2010). On the contrary, discourse prominence cues were found to be more accessible to 7 and 10 year old children whose pronoun resolution patterns appear to converge with those of adults (Argyri and Sorace, 2007; Tyler, 1983). There is growing consensus that at this age level children are able to process on-line different types of cues: lexical, syntactic and semantic, in order to identify the referent of an anaphor. This base-line difference between 5 year olds and older children (i.e. 7 and 10 year olds), as well as adults, in pronoun resolution brings out questions surrounding the robustness of discourse effects in 6 year old children. Furthermore, studies in Greek (Argyri and Sorace, 2007) revealed that, even though the production of null pronominals is adult-like at the age from $7 ; 5$ to $9 ; 7$ years, the judgment of the same constructions differs from that of adults (see section 4 ). Taking all these considerations in mind, we focused on the development of the pronoun resolution mechanism in Greek from 6 to 11 years and we directly compared the child to the adult data.

5.1.1.2. Design and procedure. We employed an on-line sentence picture matching methodology based on Marinis (2007, 2008) and Marinis and Saddy (2013). In this task, a picture was presented on the computer screen for two seconds, after which the participants started listening to a sentence in a phrase-by-phrase fashion. The participants controlled the presentation of the segments by pressing a button on a push button box. Therefore, the presentation of the sentential segments was self-paced. During the temporal unfolding of each sentence, the corresponding picture-probe was continuously displayed at the center of the screen, and remained there until the participant had heard the entire sentence. As such, display of the visual scene and listening to each experimental sentence took place in a concurrent manner. Once the last segment of the recorded sentence was listened to, the picture disappeared and a question mark '?' appeared on the center of the screen for as long as the participant needed in order to decide if the sentence matched the visual scene or not. Participants responded by pressing one of two pre-specified buttons on the push button box.

Participants were taught how to press the button to hear the sentences and were given 10 practice sentences to familiarize themselves with the task. E-prime (Schneider et al., 2002) was used to present the stimuli and to record Listening Times (LTs) from the onset of each segment until the button press.

We measured the participants' responses to the matching task, in order to explore the pronoun resolution preferences at the end of the sentence. Moreover, RTs on the matching task have also been recorded in order to examine whether the participants' matching preferences are reflected in the response times. Listening Times on each region of the sentence (see example (6) below) have also been measured in order to investigate whether the resolution preferences emerge rapidly, during on-line sentence comprehension.

\footnotetext{
${ }^{6}$ We acknowledge that there are many more discourse features which regulate anaphora resolution (e.g. contrastive focus, logophoricity; see Dimitriadis (1996) among others); however, in our study we restrict our experimental conditions to the presence vs. absence of topic-shift. For this reason the prosodic contour of the experimental sentences is neutral.
} 
5.1.1.3. Materials. The material for this task comprised 10 practice sentences, 10 experimental sentences, 30 experimental pictures, 30 filler sentences, and 30 filler pictures. The experimental sentences consisted of a main clause, in which two referents were introduced, one in the subject and one in the object position, followed by an adverbial clause the subject of which was a null pronoun (see (6)).

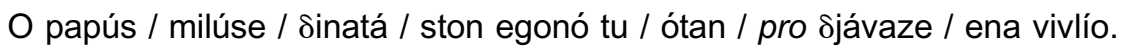

"The old-man / spoke-3SG / loudly / to his grand-child / when / pro read-PAST.3SG / a book."

The slashes in (6) indicate the way the sentence was divided into segments. The sentences were recorded by a female native speaker of Greek at a normal speaking rate always using a default intonational pattern to avoid any prosodic information effect on the participants' preferred interpretations. The recorded sentences were afterwards segmented using Cool Edit.

Each experimental sentence was matched to three different pictures. The pictures depicted the action presented in the adverbial clause and each picture provided a different interpretation: in one picture the actor was the subject of the main clause (the old man, for (6)), in the second the actor was the object of the main clause (the grand child, for (6)), and in the third the actor was a third referent (for example, a young man for (6)). An example of the experimental conditions is provided in Appendix A. Notice that all three reference interpretations are possible for a sentence such as (6). The anchoring of the null pronoun to the subject or the object or a third antecedent reflects a preference of the pronoun resolution mechanism rather than a grammatical principle (see also Dimitriadis (1996) as well Carminati (2002) for similar arguments). Therefore, there were no pre-specified correct or wrong responses to either condition. ${ }^{7}$

The critical segment in this experiment is Segment 6, i.e. the segment containing the verb of the adverbial clause (jjávaze for (6)), because at this point the action of the adverbial clause is evident and participants have to assign the thematic role of the subject. Hence, at this point it becomes clear whether or not the picture matches the sentence, i.e. it has the preferred interpretation of the sentence. If the picture does not match the participants' interpretation of the sentence, this should cause increased LTs indicating processing difficulty.

Three lists were created, each containing the 10 experimental and the 30 filler sentences. In each list, the experimental sentences were matched to one of the three pictures. Each participant encountered only one of the three lists.

To ensure that the participants listened to the sentences for comprehension, at the end of each sentence they had to judge whether or not the sentence matched the picture by pressing one of two buttons. The button press recorded the participants' judgment and also their RT for this decision. The experiment lasted approximately $30 \mathrm{~min}$.

5.1.1.4. Predictions. Based on theoretical accounts of the distribution of null pronouns in null-subject languages (see Ariel, 1990; Dimitriadis, 1996; Carminati, 2002) as well as on empirical evidence in Greek (Dimitriadis, 1996; Miltsakaki, 2001), we predict that Greek adults will exhibit a preference to interpret the null pronoun as referring to the subject antecedent, since in the experimental sentences it is the most salient referent, i.e. the topic of the sentence. This means that there should be more matches for the subject referent than the object and the third referent and the decision times at the end of the sentence should be shorter for the subject than for the object and the third referent. Moreover, assuming that pronoun resolution strategies rapidly evolve during on-line sentence comprehension, we expect that adults will exhibit shorter listening times on the critical segment, i.e. the verb, for the subject rather than the object and the third referent conditions.

Turning to the developmental data, if children have not yet acquired the relevant discourse feature, i.e. prominence of the antecedent, for pronoun resolution, we expect no differences between the subject and the object condition in the children's matches, decision times and listening times. Based on previous findings from Greek (Argyri and Sorace, 2007), we expect that null pronouns will be interpreted in an adult-like way from the age of 7 years onwards. However, if the children, at all age groups, have difficulties with the integration of the relevant discourse cue in on-line sentence processing, we expect no differences in their listening times between the subject and the object conditions but a significant preference for the subject antecedent in their matches and decision times.

Notice, however, that if the bias for the null pronominal to select a salient antecedent is not strong, as suggested by Dimitriadis (1996), we expect to find no differences between the subject and the object antecedent in either the adult or the child data.

\footnotetext{
${ }^{7}$ Since there were no pre-specified (in)correct responses to our experimental items, we decided to analyze match and mismatch responses together in the RTs on the decision task as well as in the listening times on the segments. An anonymous reviewer comments that this decision might have resulted in distortions of the results. In order to address this point, we conducted the Wilcoxon Signed Ranks non-parametric test to compare the RTs from the matches and the mismatches on the decision task for the third referent condition across the two experiments and for each experimental group. None of these differences turned out to be significant $(p>.1)$. Nevertheless, it remains to be seen whether the present findings will be replicated if a different experimental design is adopted.
} 
Regarding the third referent condition, we predict that both adults and children will exhibit weaker preference, slower decision and listening times on the condition in which the null pronoun is depicted to refer to a third referent via the accompanied picture. This prediction is based on previous findings by Tsimpli et al. (2004) on backward anaphora as well as on that the third referent is not explicitly mentioned in the sentential context, i.e. the main clause, while the subject and the object referents are mentioned in the sentence. Hence, we expect that reference to the third referent, an extrasentential one, will inflict extra processing cost relative to the subject and the object referents. However, we predict that this difference will be more pronounced in the child data, since children are more limited in their processing resources than the adults and, in particular, they disprefer reference to extra-sentential antecedents (Felser et al., 2003a,b; Sekerina et al., 2004).

\subsubsection{Results}

The experiment resulted in three types of data: (1) off-line picture matching judgment, (2) RTs on the picture matching judgments, and (3) on-line listening times. All types of data had one variable, the type of reference, with three levels (subject, object, and third reference). We analyzed each type of data by using repeated measures ANOVAs with reference (subject vs. object vs. third) as the within subjects variable and group (adults vs. child groups) as the between subjects variable.

5.1.2.1. Off-line picture matching judgment and RTs on the picture matching judgments. Graph 1 shows the participants' matches per group and condition in percentages.

A score of 5 was given when the participant replied that the picture matched the sentence and a score of 1 when the participant replied that the picture does not match the sentence. The statistical analyses have been conducted on these raw scores. There was a significant main effect of reference $\left(F 1(2,210)=199.838, p<0.001, \eta^{2}=0.656, F 2(2,72)\right.$ $\left.=76.847, p<0.001, \eta^{2}=0.681\right)$, group $\left(F 1(3,105)=7.156, p<0.001, \eta^{2}=0.170, F 2(3,36)=3.218, p<0.05, \eta^{2}=0.176\right)$, and a significant interaction between reference and group $\left(F 1(6,210)=4.592, p<0.001, \eta^{2}=0.116, F 2(6,72)=3.007\right.$, $\left.p=0.011, \eta^{2}=0.200\right)$.

In order to investigate group effects in each experimental condition, we performed planned comparisons by means of independent samples $t$-tests. The statistical tests showed that the adult data differed from the 1 st child data in both the object $(t(54)=3.209, p=0.002)$ and the third reference $(t(54)=2.505, p=0.015)$ condition. Moreover, the adult data were found to differ from the 4th/5th child data only in the object reference condition $(t(65)=4.540, p<0.001)$. Finally, 2 nd grade children were found to prefer the object antecedent significantly less frequently than 4 th/5th grade children $(t(51)$ $=2.795, p=.007)$ and similarly picked the third referent significantly less frequently than both 4 th $/ 5$ th grade $(t(51)=2.495$, $p=.016)$ and 1 st grade children $(t(40)=2.881, p=.006)$. On the other hand, the results showed that adults and 7 year olds showed a similar pattern of performance across conditions.

To further explore the interaction between reference and group we performed planned comparisons with the Bonferroni test in each group. The adult data showed that the subject reference received significantly more matches than the object $(p<0.001)$ and the third reference $(p<0.001)$ and that the object reference received significantly more

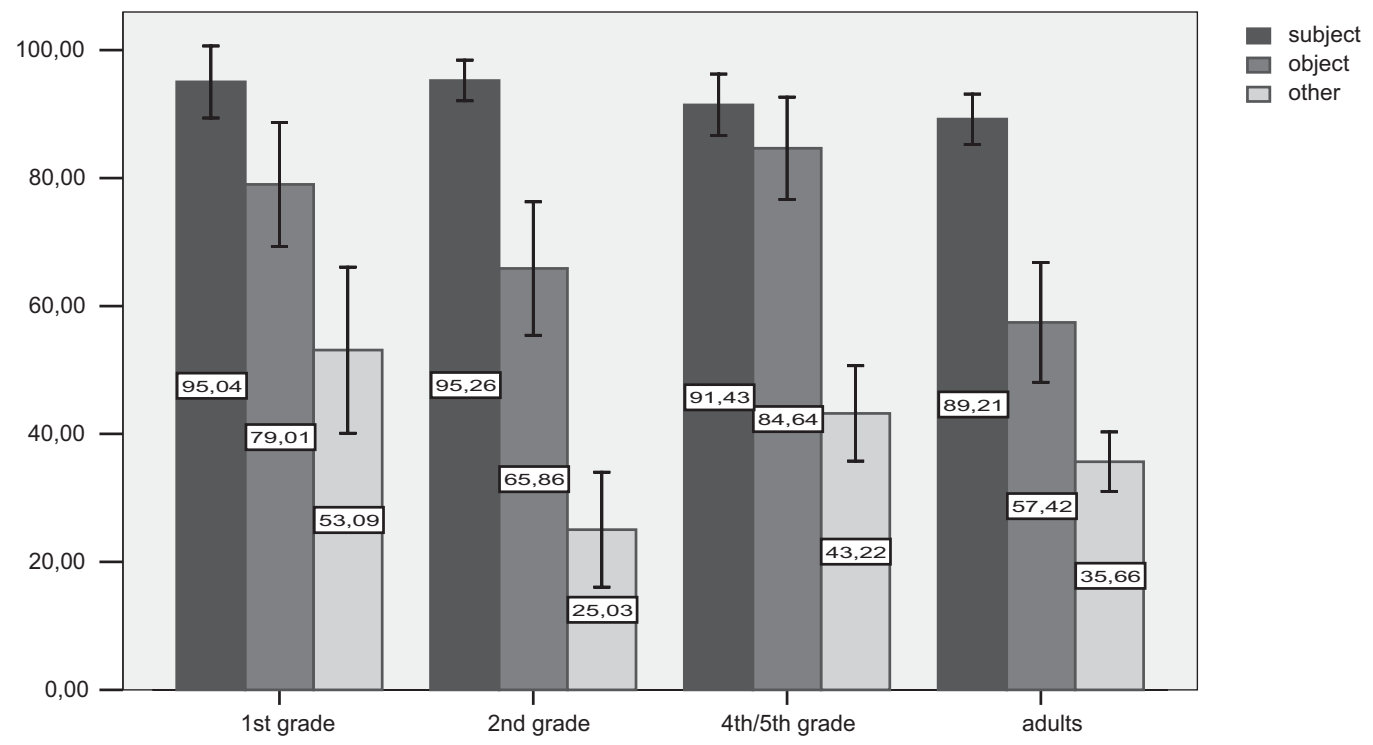

Graph 1. Adult and child matching decision preferences (\%) on null pronouns. Error bars represent SDs. 
Table 1

Adult and child data: mean RTs from the matching task with SDs in parentheses.

\begin{tabular}{llll}
\hline & \multicolumn{2}{l}{ Null pronoun } & \\
\cline { 2 - 4 } & Subject & Object & Third \\
\hline Adults & $1136(514)$ & $1522(725)$ & $1259(701)$ \\
1st grade children & $1832(594)$ & $2441(887)$ & $2684(773)$ \\
2nd grade children & $1270(495)$ & $1643(606)$ & $1842(986)$ \\
4th/5th grade children & $1365(835)$ & $1431(712)$ & $1474(692)$ \\
\hline
\end{tabular}

matches than the third reference $(p<0.001)$. Likewise, the 1 st and 2 nd grade child data showed that the subject reference received significantly more matches relative to both the object $(p=0.009$ and $p<0.001$ for 1 st and 2nd grade children, respectively) and the third reference ( $p<0.001$ for both 1 st and 2 nd child groups), while the object received considerably more matches relative to the third reference $(p<0.001$ for both 1 st and 2 nd child groups). On the other hand, the 4 th $/ 5$ th grade child data showed that both the subject $(p<0.001)$ and the object reference $(p<0.001)$ had significantly more matches than the third reference, whereas there was no significant difference between the subject and the object reference $(p>0.1)$.

Turning to the decision times on the matching task, the data in Table 1 indicate shorter RTs on the subject than the other two conditions in all groups.

There was a main effect of group $\left(F 1(3,105)=10.303, p<0.001, \eta^{2}=0.227, F 2(3,36)=9.721, p<0.001, \eta^{2}=0.448\right)$ and a main effect of reference $\left(F 1(2,210)=8.375, p<0.001, \eta^{2}=0.074, F 2(2,72)=5.611, p=0.005, \eta^{2}=0.135\right)$. Planned comparisons with the Bonferroni test for the between-group differences showed that the 1st grade children were significantly slower than the 2nd and 4th/5th grade children as well as adults $(p=0.004, p<0.001$, and $p<0.001$, respectively). To explore the reference effect obtained, we conducted planned comparisons with the Bonferroni test, which revealed that the subject condition elicited significantly shorter RTs than both the object and the third referent ( $p=0.006$ and $p=0.001$, respectively).

Even though we did not obtain an interaction between group and reference, we ran post hoc repeated measures analyses in each group as an exploratory analysis, in order to examine whether the different reference preferences among the child groups evidenced on the matches, also appear on their decision times. These analyses revealed a significant reference effect only for the 2nd grade children $\left(F 1(2,42)=4.420, p=0.018, \eta^{2}=0.174, F 2(2,18)=3.849, p=0.41\right.$, $\left.\eta^{2}=0.300\right)$ and the adults $\left.F 1(2,70)=4.516, p=0.014, \eta^{2}=0.114, F 2(2,18)=6.074, p=0.010, \eta^{2}=0.403\right)$. Paired $t$-tests showed that this effect was due to the considerably shorter RTs for the subject referent relative to the object referent $(t(21)$ $=2.610, p=0.016$ and $t(35)=3.139, p=0.003$ for 2 nd grade children and adults, respectively) and the third referent $(t(21)=2.882, p=0.009$ for the 2 nd grade children only)

5.1.2.2. On-line listening times. LTs that were 2SD above or below the mean per condition and subject were excluded from any further analyses. This affected less than $4.0 \%$ of the data. All statistical analyses were performed on raw LTs.

We measured listening times for the first six segments of our experimental items (see example 6 ). ${ }^{8}$ The critical segment is the sixth one, i.e. the subordinate verb, on which differences among the groups and the experimental conditions are expected. On the subordinate verb (Graph 2), there was a highly significant main effect of reference $(F 1(2,210)=6.118$, $\left.p=0.003, \eta^{2}=0.055, F 2(2,72)=3.731, p=0.029, \eta^{2}=0.094\right)$, but no main effect of group or interaction between reference and group. Planned comparisons with the Bonferroni test revealed that the third referent co-indexation condition elicited significantly longer LTs relative to the subject referent condition $(p=0.009)$. Exploratory post hoc analyses have also been conducted per group, despite the fact that the interaction between group and references was not significant, in order to investigate possible reference preference in on-line sentence comprehension. Separate repeated measures ANOVAs conducted for each group revealed a significant reference effect on the subordinate verb for the $1 \mathrm{st}(F 1(2,38)$ $\left.=5.542, p=0.008, \eta^{2}=0.226, F 2(2,18)=7.146, p=0.005, \eta^{2}=0.443\right)$ and the 2nd grade $(F 1(2,42)=4.566, p=0.016$, $\left.\eta^{2}=0.179 ; F 2(2,18)=2.845, p=0.069, \eta^{2}=0.240\right)$. Paired $t$-tests showed that this effect was due to considerably longer LTs for the third referent relative to the subject $(t(19)=2.947, p=0.008$ and $t(21)=2.341, p=0.029$ for 1 st and 2 nd grade, respectively) and the object referent $(t(19)=1.954, p=0.066$ and $t(21)=2.129, p=0.045$ for 1 st and 2 nd grade, respectively).

The data from the segments before the critical one (see Table B1 of Appendix B) were also statistically analyzed in order to ensure that no differences with respect to reference preferences emerge prior to encountering the critical

\footnotetext{
${ }^{8}$ Listening times on the final segment (7th) of the sentence were not recorded, since a question mark automatically appeared after the final segment was orally presented to the participants. Participants' mean LTs and SDs per sentence segment are presented in Table 1 of Appendix B.
} 


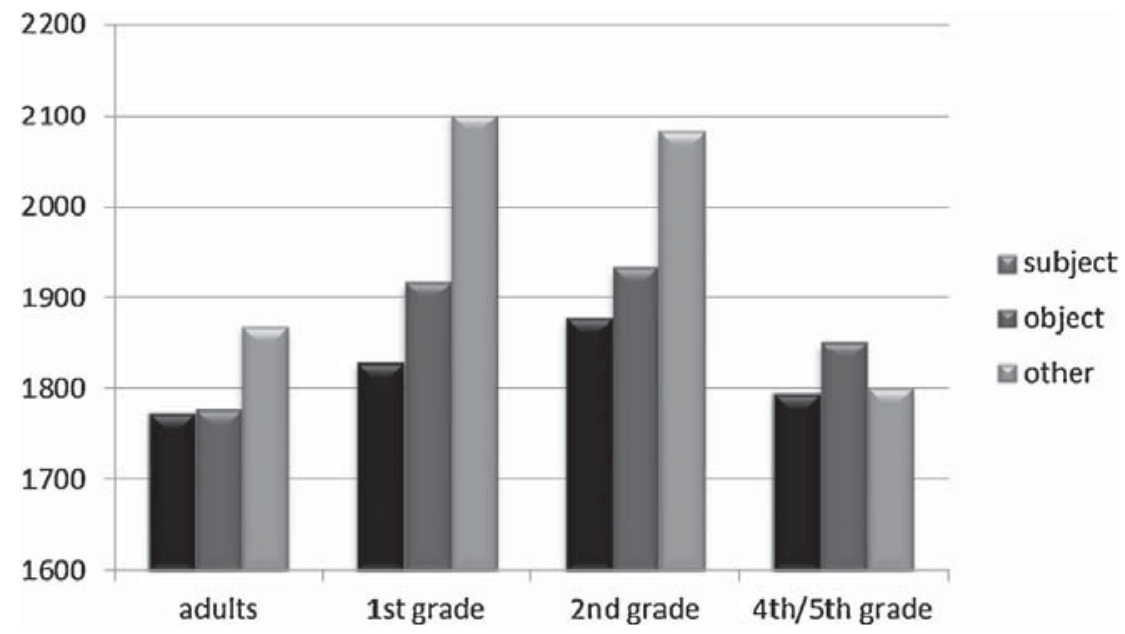

Graph 2. Adult and child mean listening times (in $\mathrm{ms}$ ) on the subordinate verb for the null pronoun experiment.

segment. Only group effects are expected on these segments, since the child listening times may be slower than the adult ones. Indeed, the only significant effect obtained was that of group (Segment 1: $F 1(3,105)=8.049, p<0.001, \eta^{2}=0.187$, $F 2(3,36)=3.533, p=0.024, \eta^{2}=0.227$; Segment 2: $F 1(3,105)=10.877, p<0.001, \eta^{2}=0.237, F 2(3,36)=6.961$, $p=0.001, \eta^{2}=0.367$; Segment 3: $F 1(3,105)=8.259, p<0.001, \eta^{2}=0.191, F 2(3,36)=6.115, p=0.002, \eta^{2}=0.338$; Segment 4: $F 1(3,105)=6.719, p<0.001, \eta^{2}=0.161, F 2(3,36)=6.669, p=0.001, \eta^{2}=0.357$; Segment 5: $F 1(3,105)$ $\left.=11.226, p<0.001, \eta^{2}=0.243, F 2(3,36)=7.372, p=0.001, \eta^{2}=0.381\right)$. Planned comparisons with the Bonferroni test showed that the adults were significantly faster than both the 1st and the 2nd grade children in the first $(p<0.001$ and $p=0.002$ for 1 st and 2 nd grade, respectively), second ( $p<0.001$ and $p=0.001$ for 1 st and 2nd grade, respectively), third ( $p<0.001$ and $p=0.002$ for 1 st and 2nd grade, respectively), fourth ( $p=0.001$ and $p=0.014$ for 1 st and 2nd grade, respectively), and fifth ( $p<0.001$ for both groups) segment.

\subsection{Experiment 2: Resolution of overt pronouns}

\subsubsection{Method}

The participants as well the design and the procedure of the second experiment were exactly the same as those of the first experiment (see section 5.1.1).

5.2.1.1. Materials. The experimental items were created exactly as the ones of the first experiment. The only difference was that the adverbial clause included an overt subject pronoun (see (7)). The two referents in the subject and the object position of the main clause always had the same gender so that the overt pronoun was compatible with both possible antecedents in terms of its gender marking.

(7) I jajá / xerétise / tin kopéla / ótan / aftí / pernúse / to Srómo.

"The old-lady / greeted-3SG / the girl / when / she / crossed-3SG / the street."

The slashes indicate the way the sentences were divided into segments. The critical segments were the overt subject pronoun and the verb of the adverbial clause. The second experiment included thirty filler items, as the first experiment. As in the null pronoun experiment, three reference conditions (subject, object and third referent) were included in this experiment too. All three reference options are considered as grammatical, for the reasons already outlined in section 5.1.1.

5.2.1.2. Predictions. Based on previous theoretical work (Ariel, 1990; Dimitriadis, 1996; Carminati, 2002) and empirical research in Greek (Dimitriadis, 1996; Miltsakaki, 2001), we predict that the Greek adults will exhibit a preference to interpret the overt subject pronoun as referring to the object antecedent, since it is not the topic of the clause preceding the one including the pronoun. This means that we will have more matches for the picture depicting the object than the subject referent as well as shorter RTs for the object than the subject referent in the decision task. If these resolution preferences emerge during on-line comprehension, shorter listening times for the object referent over the subject referent are also expected on the critical segments. Also notice that according to Dimitriadis' (1996) Overt Pronoun Rule (section 3), we predict that the bias of the overt pronoun toward non-topic antecedents will be strong. 
Regarding the developmental data, we expect no advantage for the object referent if the children have not yet acquired the discourse feature, topic shift, associated with overt pronouns. This will be reflected in their matches, decision times and listening times. However, based on previous findings (Argyri and Sorace, 2007), we expect the children to employ adult-like resolution strategies, i.e. preference for the object antecedent, from the age of 7 years onwards. If, on the other hand, children have acquired the relevant discourse feature of the overt pronouns, but instead face difficulties with its incorporation in sentence interpretation, we expect no differences between the subject and the object condition in the listening times of the critical segments, but an advantage for the object over the subject referent in the matches and the decision times.

Regarding the third referent condition, we make similar predictions as the ones for the task on null pronouns (section 5.1.1). Namely, we predict a disadvantage for the third referent in both the adult and child data, though we expect this disadvantage to be increased in the child data.

\subsubsection{Results}

In the second experiment, as in the first experiment, there was one variable, the type of reference (subject, object, and third). In each data set, we performed repeated measures ANOVAs with reference (subject vs. object vs. third) as the within subjects variable and group (adults vs. child groups) as the between subjects variable.

5.2.2.1. Off-line picture matching judgment and RTs on the picture matching judgments. First we present the data from the sentence picture matching task performed at the end of each sentence as well as on the decision times. The participants' matching decisions in percentages per group and condition are illustrated in Graph 3.

As in the experiment on null pronominals, a score of 5 was given when the participant replied that the picture matched the sentence and a score of 1 when the participant replied that the picture does not match the sentence. The statistical analyses have been run on these raw scores. There was a main effect of reference $(F 1(2,210)=61.453$, $\left.p<0.001, \eta^{2}=0.369, F 2(2,72)=17.010, p<0.001, \eta^{2}=0.321\right)$, group $\left(F 1(3,105)=17.870, p<0.001, \eta^{2}=0.338\right.$, $\left.F 2(3,36)=5.530, p=0.003, \eta^{2}=0.315\right)$, and a significant interaction between reference and group $(F 1(6,210)$ $\left.=6.266, p<0.001, \eta^{2}=0.152, F 2(6,72)=4.602, p=0.001, \eta^{2}=0.277\right)$. To explore the group effect we performed planned comparisons by means of independent samples $t$-tests comparing the performances of the four groups in each condition. These revealed that both 1 st and 2 nd grade children provided significantly more matches for the subject reference condition relative to the 4 th $/ 5$ th children $(t(49)=2.583, p=0.013$, and $t(51)=3.758, p<0.001$, respectively). Moreover, 1 st and 2 nd grade children provided considerably more matches than adults in both the subject $(t(54)=6.950, p<0.001$ and $t(56)=9.751, p<0.001$, respectively) and the third reference condition ( $t(54)$ $=3.193, p=0.002$ and $t(56)=2.092, p=0.041$, respectively). The 2 nd grade children were also found to provide considerably more matches for the object antecedent relative to the adults $(t(56)=2.099, p=0.040)$. Finally, 4 th $/ 5$ th children provided significantly more matches than adults in both the subject $(t(65)=4.379, p<0.001)$ and the object $(t(65)=2.105, p=0.039)$ reference condition .

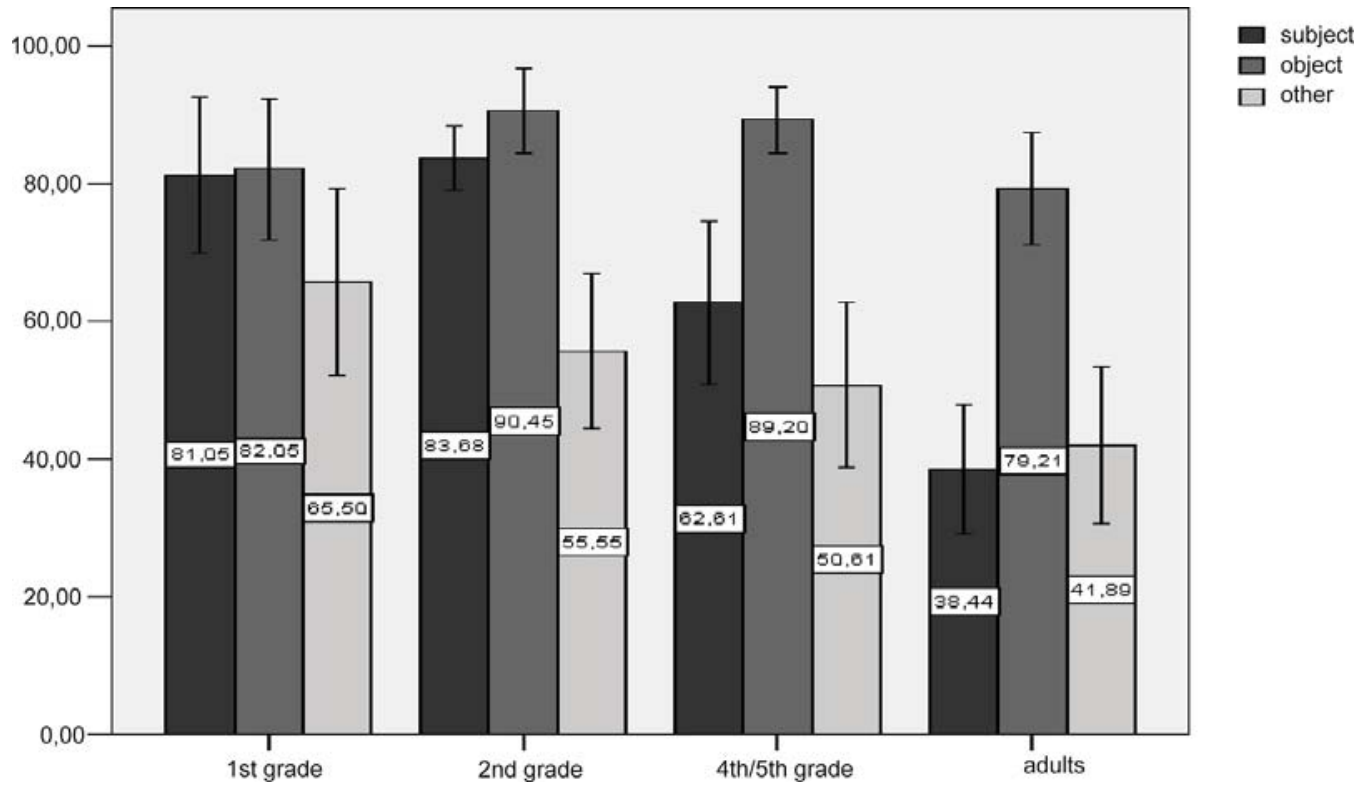

Graph 3. Adult and child matching decision preferences (\%) on overt pronouns. Error bars represent SDs. 
Table 2

Adult and child data: mean decision times form the task on overt pronouns with SDs in parentheses.

\begin{tabular}{llll}
\hline & Subject & Object & Third \\
\hline Adults & $1544(710)$ & $1272(621)$ & $1286(559)$ \\
1st grade children & $1916(845)$ & $2411(973)$ & $2703(994)$ \\
2nd grade children & $1718(547)$ & $1570(438)$ & $2467(931)$ \\
4th/5th grade children & $1732(889)$ & $1320(667)$ & $1615(710)$ \\
\hline
\end{tabular}

Furthermore, due to a significant interaction between group and reference we performed planned comparisons with the Bonferroni test in each group. These analyses showed that both 1 st and 2 nd grade children provided significantly less matches for the third referent relative to the object ( $p=0.05$ and $p<0.001$ for 1 st and 2nd grade children, respectively) and that 2 nd grade children provided significantly less matches for the third referent relative to the subject $(p<0.001)$. In addition, there was no significant difference between the subject and the object reference in either the 1st grade or the second grade group ( $p>0.1$ for both groups). The same tests showed that both the adult and the 4th/5th children provided more matches for the object than the subject $(p<0.001)$ and the third $(p<0.001)$ reference.

The decision times for the matching task are displayed in Table 2.

There was a main effect of reference $\left(F 1(2,210)=8.945, p<0.001, \eta^{2}=.062, F 2(2,72)=7.132, p=0.001, \eta^{2}=.165\right)$, group $\left(F 1(3,105)=12.255, p<0.001, \eta^{2}=.259, F 2(3,36)=5.687, p=0.003, \eta^{2}=.322\right)$, and a significant interaction between reference and group $\left(F 1(6,210)=5.733, p<0.001, \eta^{2}=.141, F 2(6,72)=3.053, p=0.010, \eta^{2}=.203\right)$. Planned comparisons with the Bonferroni test for the factor reference revealed that RTs on matching decisions for the extrasentential referent were significantly slower than the decisions for the subject and the object referent $(p=0.009$ and $p<0.001$, respectively). Planned comparisons with the Bonferroni test for the group effect showed that the 1st graders were significantly slower than the 4 th/5th graders and the adults $(p<0.001$ for both comparisons), while the 2 nd graders were significantly slower than the adults $(p=0.008)$.

To further explore the direction of the significant interaction between group and reference, we ran separate repeated measures post hoc analyses for each group. These analyses revealed a significant reference effect for all groups; $\left(F 1(2,38)=3.122, p=0.05, \eta^{2}=.141, F 2(2,18)=3.836, p=0.41, \eta^{2}=.299\right)$ for the 1st grade, $(F 1(2,42)=23.025$, $\left.p<0.001, \eta^{2}=.523, F 2(2,18)=11.096, p=0.001, \eta^{2}=.552\right)$ for the 2 nd grade, $F 1(2,60)=3.652, p=0.032, \eta^{2}=.109$, $\left.F 2(2,18)=5.092, p=0.018, \eta^{2}=.361\right)$ for the 4 th/5thgrade, and a marginally significant reference effect for the adults; $F 1(2,70)=2.626, p=0.080, \eta^{2}=.070$; (no such effect was observed on the $F 2$ analysis). Post hoc paired-samples $t$-tests showed that this effect was due to considerably shorter RTs for the subject relative to the third referent $(t(19)$ $=2.502, p=0.022$ ) for the 1st grade, significantly longer RTs for the third relative to the subject and the object referent $(t(21)=5.825, p<0.001$ and $t(21)=4.830, p<0.001$, respectively) for the 2 nd grade, considerably shorter RTs for the object relative to the subject and the third referent $(t(30)=3.063, p=0.005$ and $t(30)=1.876, p=0.070$, respectively) for the 4th/5th grade, and, finally, significantly shorter RTs for the object relative to the subject referent $t(35)=1.975$, $p=0.05)$ for the adults.

5.2.2.2. On-line listening times. LTs that were $2 \mathrm{SD}$ above or below the mean per condition and subject were excluded from any further analyses. This affected less than $3.6 \%$ of the data. All statistical analyses were performed on raw LTs.

As in the experiment on null pronominals we analyzed the listening times from the first six segments (see example 5). ${ }^{9}$ The critical segment in this task is the subordinate verb (6th segment). However, listening times on the overt pronoun (5th segment) may also be informative about the processing of referring expressions. On the overt pronoun (Graph 4), there was a main effect of group $\left(F 1(3,105)=7.907, p<0.001, \eta^{2}=0.184, F 2(2,72)=3.731, p=0.029, \eta^{2}=0.094\right)$, but no main effect of reference or an interaction between reference and group. The group effect was further examined by means of planned comparisons with the Bonferroni test, which revealed that the group effect was due to the considerably faster responses of the adult group relative to the 1 st $(p=0.001)$ and 2 nd grade children $(p=0.001)$. Even though we did not obtain a significant interaction between group and reference, we ran post hoc analyses as exploratory measures in order to examine how reference properties emerge on-line in each group. Separate repeated measures analyses conducted for each group revealed a significant reference effect on the overt pronoun $\left(F 1(2,42)=5.170, p=0.010, \eta^{2}=0.198, F 2(2,18)\right.$ $=6.479, p=0.008, \eta^{2}=0.419$ ) for the 2 nd grade children only. Paired $t$-tests showed that this effect was due to significantly longer LTs for the subject referent relative to the object and the third referent $(t(21)=2.290, p=0.032$ and $t$ (21) $=2.259, p=0.035$, respectively).

\footnotetext{
${ }^{9}$ Participants' mean LTs and SDs per segment are presented in Table 2 of Appendix B.
} 


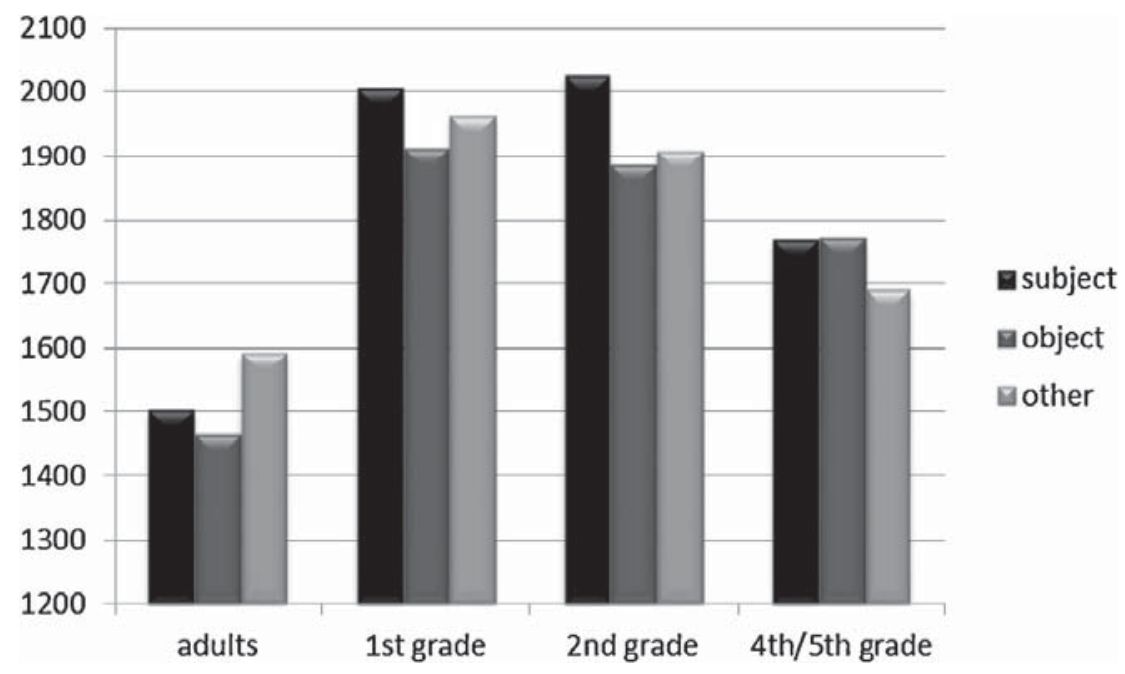

Graph 4. Adult and child mean listening times (in ms) on the pronoun for the overt pronoun experiment.

On the subordinate verb (Graph 5), there was a main effect of reference $\left(F 1(2,210)=4.166, p=0.017, \eta^{2}=0.038\right.$, $\left.F 2(2,72)=3.731, p=0.029, \eta^{2}=0.094\right)$, but no main effect of group or an interaction between reference and group. We conducted planned comparisons with the Bonferroni test to investigate the direction of the reference effect. These comparisons revealed that the subject referent elicited significantly slower LTs than the object referent $(p=.0 .031)$.

The data from the segments before the critical one (see Table B2 of Appendix B) were also statistically analyzed in order to ensure that no differences with respect to reference preferences emerge prior to encountering the critical segment. Only group effects are expected on these segments, since the child listening times may be slower than the adult ones. Indeed, the only significant effect obtained was that of group. In the first five segments, there was a significant effect of group (Segment 1: $F 1(3,105)=6.265, p=0.001, \eta^{2}=0.152, F 2(3,36)=3.533, p=0.024$, $\eta^{2}=0.227$; Segment 2: $F 1(3,105)=16.428, p<0.001, \eta^{2}=0.319, F 2(3,36)=6.961, p=0.001, \eta^{2}=0.367$; Segment 3: $F 1(3,105)=7.178, p<0.001, \eta^{2}=0.170, F 2(3,36)=6.115, p=0.002, \eta^{2}=0.338$; Segment 4: $F 1(3,105)=8.380$, $p<0.001, \eta^{2}=0.193, F 2(3,36)=6.669, p=0.001, \eta^{2}=0.357$; Segment 5: $F 1(3,105)=7.907, p<0.001, \eta^{2}=0.184$, $\left.F 2(3,36)=7.372, p=0.001, \eta^{2}=0.381\right)$. Planned comparisons with the Bonferroni test showed that the adults were significantly faster than all the child groups (i.e. the $1 \mathrm{st}$, the 2 nd and the 4 th/5th grade children) in the first ( $p=0.001, p=0.011$ and $p=0.05$, respectively), second $(p<0.001, p<0.001$ and $p=0.039$, respectively), third ( $p=0.001$ and $p=0.002$ for 1 st and 2nd grade, respectively) and fourth $(p=0.001, p<0.001$ and $p=0.05$, respectively) segment.

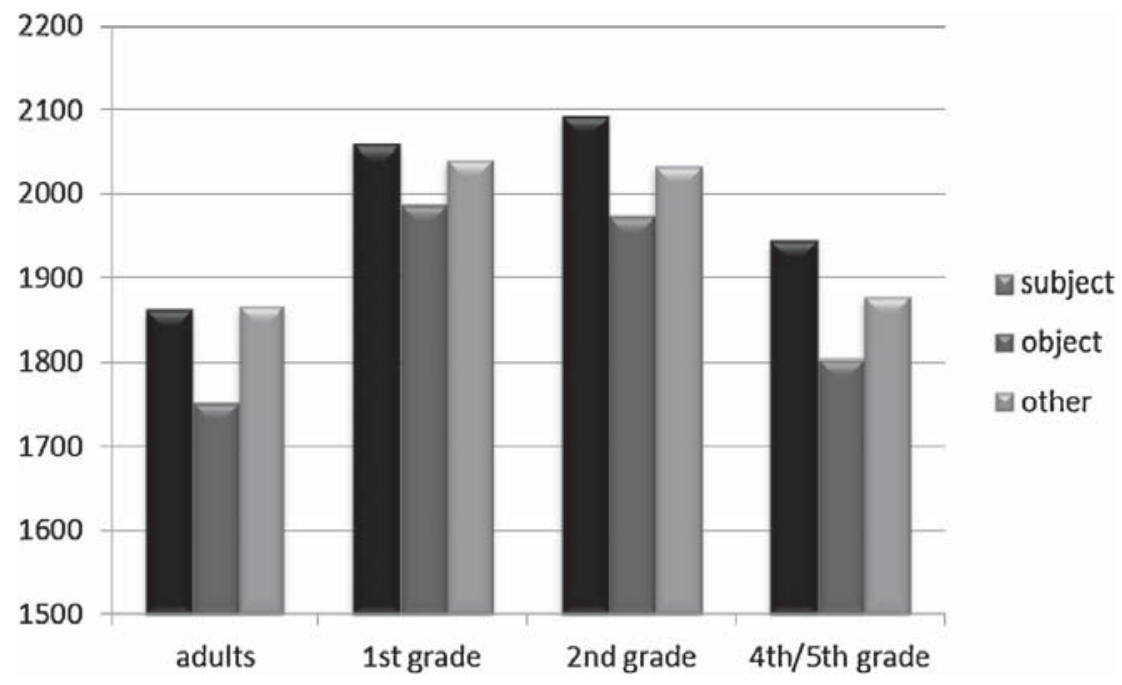

Graph 5. Adult and child mean listening times (in $\mathrm{ms}$ ) on the subordinate verb for the overt pronoun experiment. 


\section{Discussion}

The data from the two on-line sentence picture matching tasks showed that (a) children and adult participants had different preferences in the interpretation of null and overt pronouns and (b) there were differences between adults and the various child groups on the strategies employed in pronoun resolution. Before proceeding to the discussion of the present data, we provide a short summary of our main findings. The experiment on null pronouns indicated that adults as well as 1st and 2nd graders exhibited a significant preference for the subject referent over the object and the third referent, while the 4th and 5th graders did not manifest such a preference; moreover, the older children, from 10 to 11 years exhibited a dispreference for the third referent over the other two conditions. However, the decision times on the matching task from all groups showed an advantage for the subject referent over the other two conditions, while the listening times on the critical segment revealed that the subject referent was faster than the third referent condition. Turning to the overt pronoun task, the adults as well as the 4th and 5th graders significantly preferred the object antecedent over the subject and the third ones. Such a difference was not attested in the data from the younger children (1st and 2nd grades), who only dispreferred the third referent over the object (both the 1st and 2nd graders) and the subject referent (only the 2nd graders). These groups' resolution routines were also reflected in their decision times on the matching task. Nevertheless, the listening times on the subordinate verb indicate that all groups processed the object referent faster than the subject referent condition. Finally, the between-group comparisons on the matches for the null pronoun demonstrated that the children at the ages of 6 years as well as 10-11 years provided significantly more matches for the object and the third referent compared to the adults and the 2nd graders. The same comparisons for the overt pronoun showed that the 1 st, 2 nd and 4th graders matched the subject referent picture to the sentence significantly more frequently than the adults, while the younger groups' ( 6 and 7 years old) matches on this condition were significantly more frequent than those form the 4 th and 5 th graders. The 1 st and 2 nd graders further differed from the adults in that they provided significantly more matches for the third referent condition. The between-group comparisons on the decision only indicated slower response times for the 1 st and 2 nd graders compared to those of adults in the null pronoun task. Finally, the 1 st and 2 nd graders exhibited slower listening times on the overt pronoun than the adults. In what follows, we will first discuss the adult data and we will then proceed to the discussion of the child data; both data sets will be discussed in relation to the accounts and the studies outlined in sections 3 and 4 .

Our prediction regarding the resolution of null pronouns in adults has been verified by our data. More specifically, the Greek adults preferred to link null pronominals with salient/prominent referents, topic antecedents for our sentences. This finding replicates previous results from other null subject languages, such as Italian (Carminati, 2002; Filiaci, 2010), Spanish (Alonso-Ovalle et al., 2002; Filiaci, 2010; Jegerski et al., 2011; Keating et al., 2011) and Catalan (Mayol and Clark, 2010) as well as Greek (Miltsakaki, 2001). Our findings, however, do not converge with Dimitriadis' (1996) Greek corpus data and Tsimpli et al.'s (2004) Italian experimental data. In these studies the null pronominal was not found to exhibit a significant preference toward topic antecedents. One difference between our study and Tsimpli et al.'s study is that the participants in the latter were simultaneously presented with three pictures illustrating all three possible reference options, the subject, the object and the third referent, and were asked to choose the one that best illustrated the sentential meaning. This procedure may have resulted in higher activation of the object referent as a possible antecedent for a null pronoun than in our experiment. On the other hand, the overt pronoun is the marked option in null subject languages and, thus, its antecedent resolution pattern is more constrained, as we further argue below. Additionally, Dimitriadis (1996) argues that the exceptional cases in his corpus data indicate that salience/prominence can be overridden by other factors, such as animacy or agentivity; this claim is consistent with the unmarked status of the null subject pronoun and its topic interpretation bias being weaker than the non-topic bias for the overt pronoun. It is possible that the topic bias for null pronominals becomes established in adults as a consequence of the contrast with overt pronouns which carry the [topic shift] discourse feature and, hence, exhibit a preference toward non-topic antecedents.

Our prediction with respect to the overt pronominals has also been supported by our data, in that the Greek adults interpreted the overt pronoun as indicating topic shift. The overt pronoun data are similar to those reported by Carminati (2002), Filiaci (2010) and Tsimpli et al. (2004) for Italian, by Mayol and Clark (2010) for Catalan as well as by Dimitriadis (1996) and Miltsakaki (2001) for Greek. Again a discrepancy is attested between our data set and that from Spanish studies (Alonso-Ovalle et al., 2002; Filiaci, 2010; Jegerski et al., 2011; Keating et al., 2011), in which the overt pronoun bias for non-topic antecedents was not significant. Filiaci attributes the divergence between the Italian and the Spanish data to the nature of pronominal forms. Namely, the Spanish pronominals él and ella are structurally deficient, in the sense of Cardinaletti and Starke (2001), as they are weak pronouns and co-refer with topic antecedents (Filiaci, 2010:180). The Italian experimental sentences, on the other hand, included strong pronominals, such as lui and lei, which are strongly biased toward non-prominent antecedents. Notice that the Greek pronouns used in the present study, though unstressed, are strong pronominal forms and, thus, Filiaci's explanation seems to reconcile the conflicting data in the three languages. 
Building on work by Carminati (2002) and Dimitriadis (1996), we argue that anaphora resolution in Greek is constrained by grammatical and discourse factors. The grammatical constraints are related to the null-subject property of Greek and the possibility of using an overt or a null pronoun to refer back to an antecedent; in other terms, the Greek grammar provides the speaker with two pronoun forms (null vs. overt). Grammatical constraints necessitate morphological agreement in gender and number between the pronoun and its antecedent. Moreover, we claim that overt pronominals carry the discourse feature [topic shift] in their lexical entries, while null pronouns do not. ${ }^{10}$ Notice that this assumption shares similarities with Dimitriadis' (1996) Overt Pronoun Rule, according to which overt pronouns should not be construed with prominent antecedents. However, we differ from Dimitriadis' account in that we claim that the feature [topic shift] is a discourse, and not a grammatical, feature. As such, the feature has an impact on the interpretation of the sentence at the pragmatic level. ${ }^{11}$ Hence, we agree with Carminati (2002) who argues that pronoun resolution routines are guided by pragmatic principles and represent preferences and not (un)grammaticalities (see also Tsimpli and Sorace (2006) for a similar point), building on the difference between categorical judgments indicating (un)grammaticality as opposed to interpretation biases indicating a discourse interface phenomenon. ${ }^{12}$ Therefore, in cases of competing antecedents, such as the sentences of our experimental study, there are no grammatical requirements which would impose a specific choice of an antecedent, since both antecedents shared the same $\varphi$-features. More specifically, the presence of an overt pronoun activates the discourse feature [topic shift] and, hence, prefers a non-topic antecedent. On the other hand, the null pronoun is not accompanied by a specific discourse feature and, thus, it preferably refers to the most prominent antecedent. Furthermore, we maintain that the discourse feature [topic shift] is not exclusively associated with a specific syntactic position but with any syntactic position preferably used for topics. ${ }^{13}$

A final point we would like to make regards on-line processing of ambiguous pronouns. The adults' pronoun resolution preferences are also evident on their decision times for both experiments, showing a time advantage for the subject antecedent in the null pronoun experiment and for the object antecedent in the overt pronoun task. Moreover, their listening times on the critical segment indicate that pronoun resolution preferences emerge early, on the disambiguating segment, as already shown by other on-line studies (Carminati, 2002; Filiaci, 2010; Mayol and Clark, 2010). Notice, however, that, even though in the overt pronoun experiment the object referent condition was faster than the subject one, in the null pronoun task the subject referent condition was not faster than the object one. This finding indicates that, as soon as the discourse feature [topic shift] is instantiated by means of an overt pronominal, anaphor resolution is immediately guided to the preferred antecedent. On the other hand, the resolution preferences of the null pronominal do not become apparent instantaneously. According to our account, null pronominals are not specified for discourse features, such as [topic shift], and, thus, do not directly point toward the preferred antecedent. ${ }^{14}$ Notice that this finding can also be accounted for by Dimitriadis (1996) who predicts non-categorical resolution patterns for null pronominals.

Turning to the child data, we found that all child groups differentiate between null and overt pronouns, which implies that the children from the age of 6 years show awareness for the different resolution preferences of the two referring expressions tested in the present study. However, the resolution patterns for null and overt pronouns is not adult-like in

\footnotetext{
${ }^{10}$ As one reviewer pointed out, overt pronominals in Greek are associated with other discourse features too, such as focus or contrastive topics (see section 2), which are standardly assumed to be structurally and not lexically encoded and can also have effects on the interpretation of the sentence. However, our account is not incompatible with the syntactic realization of Focus and Contrastive Topic features, since they can co-exist with discourse features which are lexically encoded, such as [topic shift]. The issue definitely needs further consideration and research. However, the postulation of a theoretical account that fully explains all facts about pronoun resolution in Greek and the exact way features in the lexical entry have morphosyntactic and interpretation effects lie beyond the scope of the present paper.

11 One reviewer questioned the advantage of postulating a [topic shift] discourse feature as opposed to an interpretation bias. Given that the feature is associated with the phonological realization of the subject pronoun (null vs. overt), we assume that a feature specification is more appropriate for the lexical level.

${ }_{12}$ Mayol (2010) as well as Mayol and Clark (2010) employ the mathematical framework of game theory in order to propose a unified account for pronoun resolution patterns. This approach is an attempt to capture the fact that pronoun resolution is not categorical but rather reflects ranked preferences. The theoretical model postulated by Mayol (2010) as well as Mayol and Clark (2010) is built on the probabilistic strength of various features in pronominal resolution. However, the present data cannot be used to further evaluate this approach, since we experimentally manipulated only one discourse feature, i.e. [topic shift].

13 In the studies by Miltsakaki (2007) and Peristeri and Tsimpli (2013), who tested object preposing in focus and clitic-left dislocation structures respectively, the interpretation of the overt pronoun as referring to the patient argument and to the non topicalized antecedent is the same in both SVO and object preposed structures. These findings argue in favor of our claim that the feature [topic shift] is not associated with a specific syntactic position.

14 The time advantage for the object antecedent in the overt pronoun experiment was obtained not on the pronoun itself but on the verb following it. In the null pronoun experiment, however, the segment following the verb, which is the first segment available for referential processing, cannot be measured for LTs and, therefore, our claim about the earliness of overt pronoun resolution cannot be conclusive. We thank an anonymous reviewer for pointing this out.
} 
any of the child groups. We take this finding as indicating that, though the grammatical constraints regulating anaphora resolution are in place, the relevant discourse features are not appropriately exploited.

The data from the 1 st and 2 nd grade children do not support our prediction that the children at the age of 7 employ adult pronoun resolution strategies. In the null pronoun condition, 1st and 2nd grade children behave like adults, in that they exhibit a subject referent preference. However, they do not distinguish between the subject and the object antecedent in the overt pronoun experiment. Children at the age of 6 seem to have acquired that null pronouns in Greek are unspecified in terms of discourse related features and generally refer to prominent entities. On the other hand, the lack of a clear interpretive preference for the object antecedent at this age reveals their inability to successfully employ the discourse feature [topic shift] of the overt pronoun to interpret the sentence. Moreover, these pronoun resolution patterns are also reflected in the 6- to 7-year-old children's decision times on the matching task, as did the adults' ones. The listening times on the critical segment of the null pronoun task revealed lack of the subject referent advantage over the object one. This finding was also attested in the adult listening time data and, as already argued, may be attributed to the underspecification of null pronouns regarding discourse features (see also footnote 14). What is interesting, however, is that 6- to 7-year-old children do not differ form the adults in the listening times on the critical segment of the overt pronoun experiment; namely, they also exhibit faster listening times for the object rather than the subject referent. The exploratory analysis on the overt pronoun, even though it cannot provide any conclusive cues, seems to corroborate this finding: seven year old children's online listening times on the overt pronoun region reflected sensitivity to the [topic shift] feature of overt pronouns, yet, children at that age failed to employ this feature at an interpretative level. This means that the discourse feature [topic shift] is evaluated during sentence processing and it is only when interpreting the sentence that this option is not favored. This finding is parallel to that attested in Sekerina et al.'s (2004) study, in which the children were aware of the various referring options during sentence comprehension, while these options did not affect the final interpretation of the sentence. One possible explanation for this finding is that 4-year-old children have correctly specified the lexical entry of the overt pronoun for the discourse feature [topic shift] but the integration of the feature in the sentential meaning is not yet fully established (Arnold et al., 2007; Clahsen and Felser, 2006).

The data from the 10- to 11-year-old children further disprove our predictions regarding the child data. Namely, the 4th and 5th graders display different pronoun resolution routines than those observed in adults and the two younger child groups. In the null pronoun experiment, there were no biases to link the null pronoun to the subject antecedent, a pattern that deviates from that attested in the adults and in the two younger child groups. However, in the overt pronoun experiment, the older (10 to 11 year old) child group interpreted overt pronouns as referring back to object antecedents, in the same way as adults did. This preference indicates that the discourse related feature, i.e. topic shift, was successfully integrated at the end of the sentence. These interpretative preferences are also reflected in their decision times, particularly in the overt pronoun task. The listening times on the critical segment are not any different from the ones reported for the adults and the two younger groups: no preferences emerge in the on-line processing of the pronoun, while they do emerge in the on-line processing of the overt pronoun.

Our child data from the overt pronoun experiment point to clear developmental patterns, as the discourse feature [topic shift] seems to have been successfully acquired and adequately employed in sentence comprehension by the age of 10 years onwards, while younger children experience difficulties with this feature. On the other hand, the fact that the 10-and 11-year-old children do not manifest the subject preference for the null pronouns, while the younger children do, implies a non-steady, U-shaped development. First of all, none of the groups exhibited the subject preference during the parsing of the sentence, which suggests that the null pronominal is an underspecified form as far its discourse features are concerned and, thus, allows for more reference possibilities. The younger children's preference for the subject referent may reflect a universal preference for topic continuity by means of pronominals (Mayol and Clark, 2010; Walker et al., 1998) as well a general preference of unmarked pronominals to refer to salient/prominent antecedents, because these are more activated and more important for sentence comprehension (Gordon et al., 1993). On the other hand, the 10-to-11year-old children may discover exceptions to this pattern, leading to a period of reorganization and a temporary drop in their bias for subject reference. For example, overt pronominals are used for contrastive topics (see example (3) of section 2); in addition, null pronominals may also refer to non-topics depending on other factors such as animacy, agentivity or the "discourse point of view", as Dimitriadis' (1996) analysis and corpus data suggest. We, thus, claim that the subject prominence bias in null pronoun contexts is still developing at the age of 10-to-11 through exposure to counterevidence as the one presented above. It remains to be seen at what age the subject bias is fully established in the null pronoun resolution mechanism.

Our findings from the child data appear to contradict results from naturalistic production from 2-to-3-year-old Greek children who seem to use null and overt pronouns in pragmatically appropriate contexts (Tsimpli, 2005). It should be pointed out, however, that the contexts in which overt pronouns are employed involve contrastive or deictic sentences. In these utterances either overt pronominals or full DPs are used by the children, while the frequency of each construction is not provided in Tsimpli's (2005) study. Moreover, Tsimpli (2005) does not provide a detailed description of all the discourse features that were relevant to the production of overt subjects. Therefore, a direct comparison between our 
results and those in Tsimpli's study is not possible. Also notice that the topic-shift context which we tested in these experiments, is computationally more complex because there is competition between two compatible antecedents in the immediately preceding clause. This condition is totally different from that occurring in natural production data, in which the child on her own selects the focused antecedent for overt subjects. Furthermore, our findings also appear to not converge with Argyri and Sorace's (2007) results. The Greek children tested in the present study have not fully acquired the pronoun resolution routines at the age of 7 years, while at the same age Greek children always produced a null pronominal in topic continuity contexts. However, in the acceptability judgment used by Argyri and Sorace the children accepted overt pronouns in such contexts, similarly to what our 10- and 11-year-old children did. These discrepancies between production and comprehension certainly require further research.

A further finding that needs some discussion is the difference between adults and children in the matches of the two experiments. Namely, the 1st graders as well as the 4th graders provided more matches for the object and the third referent than the adults and the 2 nd graders in the null pronoun task. On the one hand, this finding further corroborates the 4th and 5th graders' lack of preference for the subject referent in the null pronoun task. Additionally, it indicates that, even though the 1 st graders behaved like the 2 nd graders and the adults in terms of their resolution preferences for the null pronominal, 1st graders' pronoun resolution mechanism appears not to be stable. We think that the null pronominal is more ambiguous for these child groups (1st graders as well as 4th and 5th graders) than for the 2nd graders and the adults. For the 1 st graders this ambiguity results from their reluctance to confidently reject a possible interpretation, while for the 4th and 5th graders this ambiguity is a very property of their resolution strategies at this stage (see discussion above). On the other hand, 1st and 2nd graders provided more matches for the subject and the third referent compared to the 4th and 5th graders as well as the adults in the overt pronoun experiment. This is due to the fact that the discourse feature [topic shift] has not been appropriately incorporated in the resolution routines at these ages, as also discussed before. However, the 2nd, 4th and 5th graders provided more matches for the object referent than adults in the overt pronoun experiment. Moreover, the 4th and 5th graders provided more matches for the subject and the object referent than the adults. This general picture may indicate that pronominal reference comprises a greater degree of ambiguity in children than in adults and, hence, that children are overall less prone to reject a possible interpretation.

Our prediction with respect to the difficulty of the pronoun referring to a third referent is partially supported by the data. The adults were found to disprefer the third referent in the null pronoun condition, while in the overt pronoun condition this option was not significantly distinguished form the subject reference. Furthermore, the decision times and the listening times did not exhibit significantly longer response times relatively to the other two conditions, albeit the listening times on the critical segment of the null pronoun experiment. It seems, thus, that the third referent is never preferred over the subject and the object referent for the null or the overt pronoun, though this choice appears to be regulated by the pronominal form, as the overt pronoun was more likely to attract a third referent than the null pronoun. This result with regard to the third referent is similar to the resolution preferences attested in Italian (Tsimpli et al., 2004). It remains to be seen, however, whether the third referent will attract the overt pronominal in sentences involving forward anaphora as in Tsimpli et al.'s (2004) study. On the other hand, all three child groups irrespective of age were found to dislike that option. This is because the third referent option was the least preferred one in both experiments, while the child responses on the third referent condition were elevated compared to the other two conditions (particularly evident on the decision times of the overt pronoun task). We could claim that the activation of the discourse representation of an extra-sentential referent in the children's working memory was costly and, hence, not dispreferred (see Sekerina et al., 2004 for a similar finding), but not strong enough to affect their referential decisions.

Finally, in both experiments, we found that the first five segments were processed by 1st and 2nd graders slower than adults. Such a slow-down effect possibly reflects high integration costs for the specific experiment. The fact that these listening-time differences were reported only for the younger child groups of the study suggests that young children had difficulty switching or/and allocating attention to the different demands of the task. This slow-down effect observed in these groups of children may have affected their inability to appropriately use the discourse feature [topic shift] when interpreting the overt pronoun sentences, though they showed awareness of the feature during parsing. Recall that the exploratory analysis on the listening times of the overt pronoun revealed sensitivity to the [topic shift] feature, even though this did not seem to affect their final interpretative preferences.

\section{Conclusion}

The data from two on-line sentence picture matching tasks indicated that Greek adults and children manifest distinct resolution patterns for null and overt pronouns. Greek adults and the two younger (6- and 7 year old) child groups exhibited a strong preference for the subject referent in the null pronoun contexts, whereas the older (10 to 11 year old) children showed no preference for either antecedent. On the other hand, overt pronouns were preferably interpreted as referring to 
the object of the previous clause only by the adults and the older child group. These differences reflect distinct developmental trajectories of referential processing determined by the properties of each pronoun type in Greek; acquisition of discourse features encoded in the overt pronoun seems to follow a steady developmental pattern, while the subject antecedent bias for the null pronominal follows a U-shaped developmental trajectory. In sum, the results suggest that the pronoun resolution mechanism has not yet fully developed even at the age of 10-11 years.

\section{Acknowledgments}

We would like to thank four anonymous reviewers for their valuable comments on earlier versions of the paper. Our errors remain of course ours.

\section{Appendix A}

\section{Target sentence}

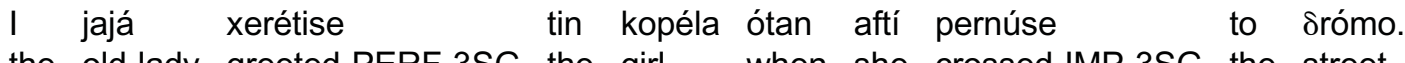

the old-lady greeted-PERF-3SG the girl when she crossed-IMP-3SG the street

"The old-lady greeted the girl when SHE crossed the street."

Picture A: Subject referent

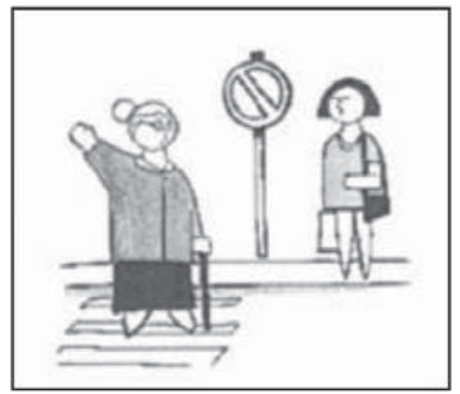

Picture B: Object referent

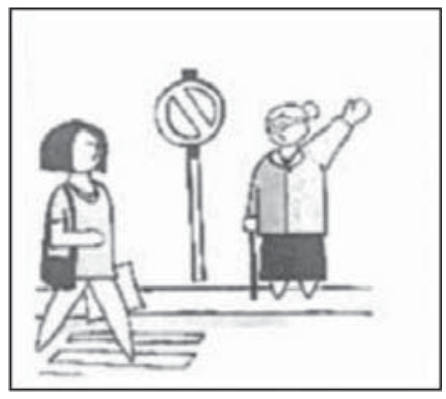

Picture C: Third referent

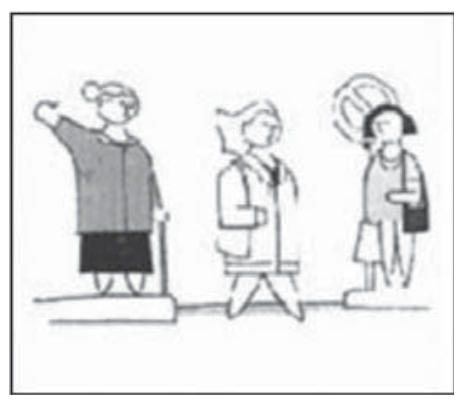




\section{Appendix B}

Table B1

Adult and child data: on-line listening times (raw data and SDs) per group, segment and referent in the null pronoun condition of the self-paced listening sentence-picture matching task.

\begin{tabular}{|c|c|c|c|c|c|c|c|}
\hline \multirow[t]{2}{*}{ Group } & \multirow[t]{2}{*}{ Referent } & \multicolumn{6}{|c|}{ Sentence items } \\
\hline & & $\begin{array}{l}\text { 1st } \\
\text { (the grandpa) }\end{array}$ & $\begin{array}{l}\text { 2nd } \\
\text { (spoke-3S) }\end{array}$ & $\begin{array}{l}\text { 3rd } \\
\text { (loudly) }\end{array}$ & $\begin{array}{l}\text { 4th } \\
\text { (to his grand child) }\end{array}$ & $\begin{array}{l}\text { 5th } \\
\text { (when) }\end{array}$ & $\begin{array}{l}\text { 6th } \\
\text { (read-3S) }\end{array}$ \\
\hline \multirow[t]{3}{*}{ 1st grade } & Subject & $2.281(784)$ & $2.086(638)$ & 2.025 (295) & $2.160(657)$ & $2.136(374)$ & $1.828(257)$ \\
\hline & Object & 2.344 (919) & 2.290 (701) & 2.142 (537) & 2.165 (429) & 1.977 (377) & 1.916 (386) \\
\hline & Other & $2.842(767)$ & $2.157(589)$ & $2.097(368)$ & $2.072(365)$ & $1.997(380)$ & 2.101 (547) \\
\hline \multirow[t]{3}{*}{ 2nd grade } & Subject & $2.240(765)$ & 1.974 (573) & $1.988(310)$ & $2.098(611)$ & $2.010(333)$ & 1.877 (385) \\
\hline & Object & $2.251(777)$ & $2.131(856)$ & $2.033(491)$ & $2.063(424)$ & $1.914(384)$ & $1.932(447)$ \\
\hline & Other & $2.737(478)$ & $2.136(529)$ & 2.061 (389) & $2.041(372)$ & $1.957(392)$ & $2.083(523)$ \\
\hline \multirow[t]{3}{*}{ 4th/5th grade } & Subject & $2.193(497)$ & $1.794(436)$ & $1.950(423)$ & $1.925(407)$ & $1.715(406)$ & $1.794(448)$ \\
\hline & Object & $2.175(809)$ & $1.922(601)$ & $1.944(573)$ & $1.936(458)$ & $1.704(317)$ & 1.851 (489) \\
\hline & Other & $2.045(655)$ & $1.728(368)$ & $1.868(407)$ & $1.918(418)$ & $1.677(357)$ & $1.802(406)$ \\
\hline \multirow[t]{3}{*}{ Adults } & Subject & $1.694(454)$ & $1.537(365)$ & $1.708(317)$ & $1.711(335)$ & $1.429(323)$ & $1.772(648)$ \\
\hline & Object & $1.713(465)$ & $1.522(388)$ & $1.615(403)$ & $1.703(396)$ & $1.420(347)$ & 1.776 (543) \\
\hline & Other & $1.692(566)$ & $1.502(350)$ & $1.646(333)$ & $1.749(391)$ & $1.454(356)$ & 1.869 (618) \\
\hline
\end{tabular}

Table B2

Adult and child data: On-line listening times (raw data \& SDs) per group, segment and referent in the overt pronoun condition of the self-paced listening sentence-picture matching task.

\begin{tabular}{|c|c|c|c|c|c|c|c|}
\hline \multirow[t]{2}{*}{ Group } & \multirow[t]{2}{*}{ Referent } & \multicolumn{6}{|l|}{ Sentence items } \\
\hline & & $\begin{array}{l}\text { 1st } \\
\text { (the grandma) }\end{array}$ & $\begin{array}{l}\text { 2nd } \\
\text { (greeted-3S) }\end{array}$ & $\begin{array}{l}\text { 3rd } \\
\text { (the girl) }\end{array}$ & $\begin{array}{l}\text { 4th } \\
\text { (when) }\end{array}$ & $\begin{array}{l}\text { 5th } \\
\text { (she) }\end{array}$ & $\begin{array}{l}\text { 6th } \\
\text { (crossed-3S) }\end{array}$ \\
\hline \multirow[t]{3}{*}{ 1st grade } & Subject & $2.711(633)$ & $2.226(562)$ & $2.035(397)$ & $1.765(326)$ & $2.006(621)$ & $2.060(333)$ \\
\hline & Object & $2.314(378)$ & $2.036(420)$ & $1.999(406)$ & $1.896(322)$ & $1.913(370)$ & $1.987(295)$ \\
\hline & Other & $2.488(682)$ & $2.278(681)$ & 2.181 (411) & 1.889 (375) & 1.964 (521) & $2.041(377)$ \\
\hline \multirow[t]{3}{*}{ 2nd grade } & Subject & $2.510(643)$ & $2.185(538)$ & 1.997 (391) & $1.806(413)$ & $2.026(582)$ & $2.093(429)$ \\
\hline & Object & $2.483(462)$ & $1.989(403)$ & 1.956 (363) & $1.882(345)$ & 1.887 (461) & 1.974 (329) \\
\hline & Other & $2.324(548)$ & $2.261(672)$ & $2.209(447)$ & 1.896 (365) & $1.909(476)$ & $2.034(444)$ \\
\hline \multirow[t]{3}{*}{ 4th/5th grade } & Subject & $2.047(778)$ & $1.787(433)$ & $1.903(493)$ & $1.717(495)$ & $1.771(450)$ & $1.945(542)$ \\
\hline & Object & $2.364(971)$ & $1.794(404)$ & $1.856(389)$ & $1.672(347)$ & $1.773(471)$ & $1.804(411)$ \\
\hline & Other & $1.990(501)$ & $1.805(330)$ & 1.861 (369) & 1.652 (329) & 1.691 (345) & $1.879(443)$ \\
\hline \multirow[t]{3}{*}{ Adults } & Subject & $1.505(321)$ & $1.506(290)$ & 1.649 & $1.449(390)$ & $1.504(310)$ & $1.863(494)$ \\
\hline & Object & $1.534(388)$ & $1.519(404)$ & 1.644 (355) & 1.449 (322) & $1.467(280)$ & 1.751 (489) \\
\hline & Other & $1.688(544)$ & $1.567(340)$ & 1.739 (406) & 1.505 (362) & $1.592(465)$ & $1.868(445)$ \\
\hline
\end{tabular}

\section{References}

Allen, S.E.M., 1997. A discourse-pragmatic explanation for the subject-object asymmetry in early null arguments: the principle of informativeness revisited. In: Sorace, A., Heycock, C., Shillcock, R. (Eds.), Proceedings of the GALA 1997 Conference on Language Acquisition. University of Edinburgh, Edinburgh.

Allen, S.E.M., 2000. A discourse-pragmatic explanation for argument representation in child Inuktitut. Linguistics 38, 483-521.

Allen, S.E.M., 2001. The Importance of Discourse-Pragmatics in Acquisition, vol. 4. Language and Cognition, Bilingualism, pp. 23-25.

Alonso-Ovalle, L., Fernandes-Solera, S., Frazier, L., Clifton, Ch., 2002. Null vs. overt pronouns and the Topic-Focus articulation in Spanish. Riv. Linguist. 14 (2), 1-19.

Altmann, G., Steedman, M., 1988. Interaction with context during human sentence processing. Cognition 30, 191-238.

Argyri, E., Sorace, A., 2007. Crosslinguistic Influence and Language Dominance in Older Bilingual Children, vol. 10. Language and Cognition, Bilingualism, pp. 79-99.

Ariel, M., 1990. Accessing Noun Phrase Antecedents. Routledge, London.

Arnold, J.E., Eisenband, J.G., Brown-Schmidt, S., Trueswell, J.C., 2000. The rapid use of gender information: evidence of the time course of pronoun resolution from eyetracking. Cognition 76, B13-B26. 
Arnold, J.E., Brown-Schmidt, S., Trueswell, J.C., 2007. Chidren's use of gender and order-of-mention during pronoun comprehension. Lang. Cognit. Process. 22, 527-565.

Brennan, S.E., Friedman, M.W., Pollard, C.J., 1987. A centering approach to pronouns. In: Proceedings of the 25th Meeting of the Association for Computational Linguistics, Stanford, CA, pp. 155-162.

Cardinaletti, A., Starke, M., 2001. The typology of structural deficiency. A case study of the three classes of pronouns. In: van Riemsdijk, H. (Ed.), Clitics in the languages of Europe, Vol. 8 of Language Typology. Mouton de Gruyter, Berlin.

Carminati, M.N., 2002. The Processing of Italian Subject Pronouns (Ph.D. dissertation). University of Massachusetts, Amherst.

Chambers, G.C., Smyth, R., 1998. Structural parallelism and discourse coherence: a test of Centering theory. J. Mem. Lang. 39, 593-608.

Clahsen, H., Felser, C., 2006. Grammatical processing in language learners. Appl. Psycholinguist. 27, 3-42.

Clancy, P., 1993. Preferred argument structure in Korean acquisition. In: Clark, E. (Ed.), Proceedings of the Twenty-fifth Annual Child Language Research Forum. CSLI, Stanford.

Clancy, P., 1997. Discourse motivations for referential choice in Korean acquisition. In: Sohn, H., Haig, J. (Eds.), Japanese/Korean Linguistics, vol. 6. CSLI Publications, Standford, CA.

Corbett, A.T., Chang, F.R., 1983. Pronoun disambiguation: accessing potential antecedents. Mem. Cognit. 11, $283-294$.

Crain, S., McKee, C., Emiliani, M., 1990. Visiting relatives in Italy. In: Frazier, L., De Villiers, J. (Eds.), Language Processing and Language Acquisition. Kluwer Academic Publishers, Dordrecht.

Dimitriadis, A., 1996. When pro-drop language don't: overt pronominal subjects and pragrmatic inference. In: Dobrin, L.M., Singer, K., McNair, L. (Eds.), Proceedings of CLS, vol. 32, pp. 33-47.

Ehrlich, K., 1980. Comprehension of pronouns. Q. J. Exp. Psychol. 32, 247-255.

Felser, C., Marinis, T., Clahsen, H., 2003. Children's processing of ambiguous sentences: a study of relative clause attachment. Lang. Acquis. 11, $127-163$.

Felser, C., Roberts, L., Marinis, T., Gross, R., 2003. The processing of ambiguous sentences by first and second language learners of English. Appl. Psycholinguist. 24, 453-489.

Filiaci, F., 2010. Null and overt subject biases in Spanish and Italian: a cross-linguistic comparison. In: Borgonovo, C., Español-Echevarría, M., Prévost, P. (Eds.), Selected Proceedings of the 12th Hispanic Linguistic Symposium. Cascadilla Proceedings Project, Somerville, MA, pp. 171-182.

Givon, T., 1983. Topic continuity in discourse: a quantitative cross-language study. In: Topic Continuity in Discourse: An Introduction. John Benjamins, Amsterdam, pp. 1-42.

Goodluck, H., 1990. Knowledge integration in processing and acquisition: comments on Grimshaw and Rosen. In: Frazier, L., De Villiers, J. (Eds.), Language Processing and Language Acquisition. Kluwer, Dordrecht.

Goodluck, H., Tavakolian, S., 1982. Competence and processing in children's grammar of relative clauses. Cognition 11, 1-27.

Gordon, P.C., Grosz, B.J., Gilliom, L.A., 1993. Pronouns, names, and the centering of attention in discourse. Cognit. Sci. 17, 311-347.

Greenfield, P.M., Smith, J.H., 1976. The structure of communication in early language development. Academic Press, New York.

Grosz, B.J., Joshi, A.K., Weinstein, S., 1995. Centering: a framework for modeling the local coherence of discourse. Comput. Linguist. 21 (2), 203-225.

Gundel, J., Hedberg, N., Zacharski, R., 1993. Cognitive status and the form of referring expressions in discourse. Language 69, $274-307$.

Hahne, A., Friederici, A.D., 2001. Processing a second language: late learners' comprehension mechanisms as revealed by event-related brain potentials. Biling. Lang. Cognit. 4, 123-141.

Hamburger, H., Crain, S., 1982. Relative acquisition. In: Kuczaj, S. (Ed.), Language Development, vol. II. Lawrence Erlbaum, Hillsdale, NJ.

Hickmann, M., Hendriks, H., 1999. Cohesion and anaphora in children's narratives: a comparison of English, French, German, and Mandarin Chinese. J. Child Lang. 26, 419-452.

Jegerski, J., VanPatten, B., Keating, G.D., 2011. Cross-linguistic variation and the acquisition of pronominal reference in L2 Spanish. Second Lang. Res. 33 (2), 193-221.

Keating, G.D., VanPatten, B., Jegerski, J., 2011. Who was walking on the beach? Anaphora resolution in Spanish heritage speakers and adult second language learners. Stud. Second Lang. Acquis. 33 (2), 193-221.

Kehler, A., 2002. Coherence, Reference and the Theory of Grammar. CSLI Publications, Stanford, CA.

Marinis, T., 2007. On-line processing of passives in L1 and L2 children. In: Belikova, A., Meroni, L., Umeda, M. (Eds.), Proceedings of the 2nd Conference on Generative Approaches to Language Acquisition North America. Cascadilla Proceedings Project, Somerville, MA, pp. 265-276.

Marinis, T., 2008. On-line processing of sentences involving reflexive and non-reflexive pronouns in L1 and L2 children. In: Gavarró, A., Freitas, M. J. (Eds.), Language Acquisition and Development. Proceedings of GALA 2007. Cambridge Scholars Publishing, pp. 348-358.

Marinis, T., Saddy, D., 2013. Parsing the passive: comparing children with specific language impairment to sequential bilingual children. Lang. Acquis. 20, 155-179.

Mayol, L., 2010. Contrastive pronouns in null subject romance languages. Lingua 120 (10), 2497-2514.

Mayol, L., Clark, R., 2010. Pronouns in Catalan: games of partial information and the use of linguistic resource. J. Pragmat. 42 (3), $781-799$.

McKee, C., Nicol, J., McDaniel, D., 1993. Children's application of binding during sentence processing. Lang. Cognit. Process. 8, $265-290$.

Meroni, L., Crain, S., 2003. How Children Avoid Kindergarten Paths. Proceedings of the 4th Tokyo Conference on Psycholinguistics. Hitsuji Shobo, Tokyo, Japan.

Miltsakaki, E., 2001. Centering in Greek. In: Mela-Athanasopoulou, E. (Ed.), Proceedings of the 15th International Symposium on Theoretical and Applied Linguistics. Aristotle University of Thessaloniki, Thessaloniki, Greece, pp. 309-327.

Miltsakaki, E., 2007. A rethink of the relationship between salience and anaphora resolution. In: Branco, A., McEnery, T., Mitkov, R., Silva, F. (Eds.), Proceedings of the 6th Discourse Anaphora and Anaphor Resolution Colloquium (DAARC 2007). Centro de Linguística de Universidade do Porto, Porto.

Montalbetti, M., 1984. After Binding (Ph.D. dissertation). MIT, Cambridge, MA.

Papadopoulou, D., Tsimpli, I., 2005. Morphological cues in children's processing of ambiguous sentences: a study of subject/object ambiguities in Greek. BUCLD 29, 471-481. 
Papangeli, A., 2010. Language Development and On-line Processing in L1 and L2 Children (Unpublished Ph.D. dissertation). University of Reading.

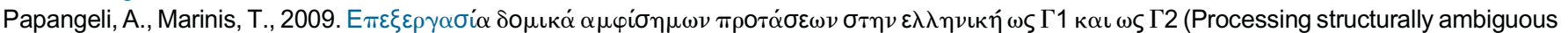
sentences in Greek as 11 and L2). Studies in Greek Linguistics, vol. 30. Institute of Modern Greek Studies, Thessaloniki, pp. $477-486$.

Pearlmutter, N.J., MacDonald, M.C., 1995. Individual differences and probabilistic constraints in syntactic ambiguity resolution. J. Mem. Lang. 34, 521-542.

Peristeri, E., Tsimpli, I., 2013. Pronoun processing in Broca's aphasia: discourse syntax effects in ambiguous anaphora resolution. Aphasiology 27 (11), 1381-1407.

Roberts, L., Marinis, T., Felser, C., Clahsen, H., 2007. Antecedent priming at gap positions in children's sentence processing. J. Psycholinguist. Res. 36, 175-188.

Schneider, W., Eschman, A., Zuccolotto, A., 2002. E-prime Reference Guide. Psychology Software Tools.

Sekerina, I., Stromswold, K., Hestvik, A., 2004. How do children and adults process referentially ambiguous pronouns? J. Child Lang. 31, $123-152$.

Serratrice, L., 2007. Null and overt subjects at the syntax-discourse interface: evidence from monolingual and bilingual acquisition. In: The Acquisition of Romance Languages: Selected papers from the Romance Turn II, pp. 181-200.

Serratrice, L., Sorace, A., Paoli, S., 2004. Cross-linguistic influence at the syntax-pragmatics interface: subjects and objects in English-Italian bilingual and monolingual acquisition. Biling. Lang. Cognit. 7, 183-205.

Song, H., Fisher, C., 2005. Who's “she”? Discourse prominence influences preschoolers' comprehension of pronouns. J. Mem. Lang. 52, $29-57$.

Song, H., Fisher, C., 2007. Discourse prominence effects on 2.5-year-old children's interpretations of pronouns. Lingua 117, $1959-1987$.

Tanenhaus, M.K., Trueswell, J.C., 1995. Sentence comprehension. In: Eimas, P., Miller, J.L. (Eds.), Handbook of Perception and Cognition: Language. Academic Press, New York.

Taraban, R., McClelland, J., 1988. Constituent attachment and thematic role assignment in sentence processing: influences of content-based expectations. J. Mem. Lang. 27, 1-36.

Traxler, M., 2002. Plausibility and subcategorisation preference in children's processing of temporarily ambiguous sentences: evidence from selfpaced reading. Q. J. Exp. Psychol. 55A, 75-96.

Trueswell, J.C., 1996. The role of lexical frequency in syntactic ambiguity resolution. J. Mem. Lang. 35, 566-585.

Trueswell, J.C., Tanenhaus, M.K., 1994. Toward a lexicalist framework for constraint-based syntactic ambiguity resolution. In: Clifton, C., Rayner, K., Frazier, L. (Eds.), Perspectives on Sentence Processing. Erlbaum, Hillsdale, NJ.

Trueswell, J.C., Tanenhaus, M.K., Garnsey, S.M., 1994. Semantic influences on parsing: use of thematic role information in syntactic ambiguity resolution. J. Mem. Lang. 33, 285-318.

Trueswell, J.C., Sekerina, I., Hill, N.M., Logrip, M.L., 1999. The kindergarten-path effect: studying on-line sentence processing in young children. Cognition 73, 89-134.

Tsimpli, I., 2005. Peripheral positions in early Greek. In: Stavrou, M., Terzi, A. (Eds.), Advances in Greek Generative Syntax. John Benjamins, Amsterdam, pp. 179-216.

Tsimpli, I.M., Sorace, A., 2006. Differentiating interfaces: L2 performance in syntax semantics and syntax discourse phenomena. In: Bamman, D., Magnitskaia, T., Zaller, C. (Eds.), Proceedings of the 30th annual Boston University Conference on Language Development, BUCLD. Cascadilla Press, Somerville, MA.

Tsimpli, I., Sorace, A., Heycock, C., Filiaci, F., 2004. First language attrition and syntactic subjects: a study of Greek and Italian near-native speakers of English. Int. J. Biling. 8 (3), 257-277.

Tyler, L.K., 1983. The development of discourse mapping processes: the on-line interpretation of anaphoric expressions. Cognition 13, 309-341.

Tyler, L.K., Marslen-Wilson, W., 1981. Children's processing of spoken language. J. Verbal Learn. Verbal Behav. $20,400-416$.

Verbuk, A., Roeper, T., 2010. How pragmatics and syntax make principle B acquirable. Lang. Acquis. 17 (1), $51-65$.

Walker, M., Joshi, A., Prince, E., 1998. Centering Theory in Discourse. Oxford University Press, New York. 